\title{
Adult Brain Serotonin Deficiency Causes Hyperactivity, Circadian Disruption, and Elimination of Siestas
}

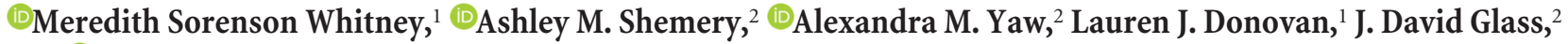 \\ and ${ }^{\circ}$ Evan S. Deneris ${ }^{1}$ \\ ${ }^{1}$ Department of Neurosciences, Case Western Reserve University, Cleveland, Ohio 44106; and ${ }^{2}$ School of Biomedical Sciences, Kent State University, Kent, \\ Ohio 44240
}

\begin{abstract}
Serotonin (5-HT) is a crucial neuromodulator linked to many psychiatric disorders. However, after more than 60 years of study, its role in behavior remains poorly understood, in part because of a lack of methods to target 5-HT synthesis specifically in the adult brain. Here, we have developed a genetic approach that reproducibly achieves near-complete elimination of 5-HT synthesis from the adult ascending 5-HT system by stereotaxic injection of an adeno-associated virus expressing Cre recombinase (AAV-Cre) into the midbrain/pons of mice carrying a loxP-conditional tryptophan hydroxylase 2 (Tph2) allele. We investigated the behavioral effects of deficient brain 5-HT synthesis and discovered a unique composite phenotype. Surprisingly, adult 5-HT deficiency did not affect anxiety-like behavior, but resulted in a robust hyperactivity phenotype in novel and home cage environments. Moreover, loss of 5-HT led to an altered pattern of circadian behavior characterized by an advance in the onset and a delay in the offset of daily activity, thus revealing a requirement for adult 5-HT in the control of daily activity patterns. Notably, after normalizing for hyperactivity, we found that the normal prolonged break in nocturnal activity (siesta), a period of rapid eye movement (REM) and non-REM sleep, was absent in all animals in which 5-HT deficiency was verified. Our findings identify adult 5-HT as a requirement for siestas, implicate adult 5-HT in sleep-wake homeostasis, and highlight the importance of our adult-specific 5-HT-synthesis-targeting approach in understanding 5-HT's role in controlling behavior.
\end{abstract}

Key words: circadian behavior; hyperactivity; serotonin; siesta; tryptophan hydroxylase

Significance Statement

Serotonin (5-HT) is a crucial neuromodulator, yet its role in behavior remains poorly understood, in part because of a lack of methods to target specifically adult brain 5-HT synthesis. We developed an approach that reproducibly achieves near-complete elimination of 5-HT synthesis from the adult ascending 5-HT system. Using this technique, we discovered that adult 5-HT deficiency led to a novel compound phenotype consisting of hyperactivity, disrupted circadian behavior patterns, and elimination of siestas, a period of increased sleep during the active phase. These findings highlight the importance of our approach in understanding 5-HT's role in behavior, especially in controlling activity levels, circadian behavior, and sleep-wake homeostasis, behaviors that are disrupted in many psychiatric disorders such as attention deficit hyperactivity disorder.

\section{Introduction}

Serotonin (5-HT) is a crucial neuromodulator in the CNS, with 5 -HT neurons innervating nearly every region of the brain

Received May 4, 2016; revised Aug. 2, 2016; accepted Aug. 3, 2016.

Author contributions: M.S.W., J.D.G., and E.S.D. designed research; M.S.W., A.M.S., A.M.Y., and L.J.D. performed research; M.S.W., A.M.S., A.M.Y., J.D.G., and E.S.D. analyzed data; M.S.W. and E.S.D. wrote the paper.

This work was supported by the National Institutes of Health (Grants P50 MH096972 and R01 MH062723 to E.S.D. and Grant F30 MH099704 to M.S.W.). We thank Katherine Lobur for assistance with mouse genotyping and breeding; Dr. Chris Ford for assistance in stereotaxic surgical training; Dr. Tiffany Rogers for assistance with stereotaxic surgeries and home cage monitoring studies at Vanderbilt University and Drs. Dan Wesson and Doug McMahon for valuable comments.

The authors declare no competing financial interests.

Correspondence should be addressed to Evan Deneris, Case Western Reserve University, School of Medicine, Department of Neuroscience, 2109 Adelbert Rd., Cleveland, OH 44106-4975. E-mail: esd@case.edu.
(Jacobs and Azmitia, 1992). Over the past six decades, a tremendous body of literature has linked 5-HT system dysfunction to highly prevalent psychiatric disorders, including major depression (Belmaker and Agam, 2008), generalized anxiety disorder (Durant et al., 2010), attention deficit hyperactivity disorder (ADHD) (Banerjee and Nandagopal, 2015), and posttraumatic stress disorder (Southwick et al., 1999). This has prompted the development of methods to deplete brain $5-\mathrm{HT}$, which has revealed numerous effects on behavior and physiology (Morin, 1999; Hodges and Richerson, 2010; Deneris, 2011; Fernandez and Gaspar, 2012; Mosienko et al., 2015).

DOI:10.1523/JNEUROSCI.1469-16.2016

Copyright $\odot 2016$ the authors $\quad 0270-6474 / 16 / 369828-15 \$ 15.00 / 0$ 
One early method for 5-HT depletion used p-chlorophenylalanine (PCPA), a competitive inhibitor of the ratelimiting enzyme in 5-HT synthesis, tryptophan hydroxylase (Tph) (Koe and Weissman, 1966). However, PCPA blocks enzymatic activity of both Tph isoforms, Tph1 and Tph2, which are mainly, but not exclusively, expressed in the periphery and the brain, respectively (Walther and Bader, 2003; Gershon, 2013; Kim et al., 2015). Furthermore, PCPA affects the levels of other monoamines directly (Tagliamonte et al., 1973) and 5-HT synthesis eventually recovers, making it difficult to assess the effects of chronic 5-HT loss (Reader and Gauthier, 1984). Another early method used the neurotoxin 5,7-dihydroxytryptamine (5,7DHT) to destroy 5-HT axon terminals and possibly cell bodies, thus removing 5-HT in terminal innervation zones (Baumgarten et al., 1973). However, apparently not widely considered is that the destruction of 5-HT terminals would be expected to decrease other signaling substances also released from these terminals, such as glutamate and neuropeptides (El Mestikawy et al., 2011; Wyler et al., 2016). Moreover, 5-HT's serotonergic specificity requires pretreatment with noradrenaline reuptake inhibitors to prevent noradrenaline loss (Björklund et al., 1975), which is not always effective (Mackenzie et al., 1978; Sziray et al., 2010), and 5-HT terminals ablated by 5,7-DHT eventually regenerate (Wuttke et al., 1977; Morin, 1992). Recent studies have questioned whether the behavioral phenotypes arising from 5,7-DHT treatment result specifically from 5-HT deficiency (Choi et al., 2004; Knuth and Etgen, 2004).

Genetic approaches have also been reported. Targeting of transcription factors Lmx1b or Pet-1, which are required for 5-HT neuron development and function, results in near-total, lifelong absence of CNS 5-HT through broad loss of Tph2 expression (Hendricks et al., 2003; Zhao et al., 2006). Loss of Lmx1b or Pet- 1 also alters the expression of numerous other genes in 5-HT neurons (Zhao et al., 2006; Wyler et al., 2016). Therefore, these approaches do not constitute models of specific 5-HT deficiency. Germline targeting of Tph2 causes a $>90 \%$ depletion of CNS 5-HT and numerous behavioral phenotypes, but it is unclear whether these phenotypes were due to abnormal development brought about by 5 -HT deficiency or to a specific requirement for 5-HT in adulthood (Gutknecht et al., 2008; Savelieva et al., 2008; Alenina et al., 2009; Migliarini et al., 2013). Recently, a tamoxifen-inducible approach targeting Tph2 in adulthood (Pelosi et al., 2015) using a ubiquitously expressed CMV-CreER (Feil et al., 1996) was described; however, it would be expected to eliminate Tph2 in all CNS and peripheral cell types in which it is expressed (Ohta et al., 2011; Gershon, 2013).

We have developed a genetic approach to target Tph2 in the midbrain/pontine raphe nuclei of the adult mouse. Highly reproducible 5-HT deficiency was achieved through stereotaxic injection of an adeno-associated virus-expressing Cre recombinase (AAVCre) into the midbrain/pons of mice carrying a loxP-flanked Tph2 allele. We investigated the effect of this deficiency on behavior and uncovered a novel phenotype characterized by hyperactivity and disrupted circadian activity patterns. We also present findings that implicate adult brain 5-HT synthesis in the control of the siesta, a period of increased sleep during the active phase. Our findings highlight the importance of targeting adult 5-HT synthesis to understand 5 -HT's role in behavior.

\section{Materials and Methods}

\section{Animals}

$T p h 2^{f l / f l}, T p h 2^{f l /+}$, and Tph $2^{f l /-}$ mice (Kim et al., 2014) were used for experiments. Male and female mice were used for molecular experiments in Figures 1, 2, and 3. Male mice only were used for all behavior experiments. Mice were housed on a 12:12 h light/dark (LD) cycle with food and water available ad libitum. Up to five mice were cohoused in a cage except where noted. All experimental procedures were conducted in accordance with the guidelines of the National Institutes of Health and were approved by Case Western Reserve University's Institutional Animal Care and Use Committee.

\section{Stereotaxic viral injections}

After induction in Isothesia (isoflurane; Henry Schein Animal Health) anesthetic $\left(3.0-3.5 \%\right.$ in $\left.1 \mathrm{~L} / \mathrm{min} \mathrm{O}_{2}\right)$, the mice were mounted into a stereotaxic frame and the anesthetic state was maintained under isoflurane. Core body temperature was maintained at $38^{\circ} \mathrm{C}$ with a heating pad. Upon confirmation of anesthesia depth, the head was shaved, cleaned with betadine and $70 \% \mathrm{EtOH}$, and a single injection of Marcaine (bupivacaine $\mathrm{HCl}$; Hospira) was administered subcutaneously within the site of the future wound margin. A single midline incision was made from $\sim 3$ $\mathrm{mm}$ posterior of the nose along the midline to $\sim 3 \mathrm{~mm}$ posterior of lambda. Two holes ( $\sim 1 \mathrm{~mm}$ diameter $)$ were drilled $\pm 0.5 \mathrm{~mm}$ from the midline of the skull $(-4.2 \mathrm{~mm}$ from bregma). A $10 \mu$ l Gastight 1701 Hamilton syringe (30 gauge needle with a $13^{\circ}$ bevel) loaded with AAV (AAV1.CMV.PI.Cre.rBG or AAV1.CMV.PI.EGFP.WPRE.bGH, Penn Vector Core, Philadelphia, PA) was lowered into the intended injection site $(-4.0 \mathrm{~mm}$ ventral) with the bevel facing midline and AAV infused at a rate of $100 \mathrm{nl} / \mathrm{min}$. For experiments using Tph $2^{f l f l}$ mice, $1 \mu \mathrm{l}$ of AAVGFP (control) or AAV-Cre (experimental) was infused per injection. For experiments using $T p h 2^{f l /+}$ and $T p h 2^{f l /-}$ mice, $0.8 \mu \mathrm{l}$ of AAV-Cre was infused at the first site and $0.4 \mu \mathrm{l}$ was infused at the second site. In the cohort used for the circadian study, the injection at each site $(X= \pm 0.9$ $\mathrm{mm}, Y=-4.2)$ consisted of two injections, one at $Z=-3.125 \mathrm{~mm}(0.6$ $\mu \mathrm{l})$ and a second at $Z=-4.2 \mathrm{~mm}(0.7 \mu \mathrm{l})$, with $7 \mathrm{~min}$ in between to allow for diffusion of the virus. In all surgeries, 10 min elapsed at the end of the injection at each site to allow for diffusion of the virus before the syringe was slowly raised out of the brain and the process was repeated at the second site. After the final injection, the craniotomies and scalp were closed. Rimadyl (carprofen, $5 \mathrm{mg} / \mathrm{kg}$, s.c.; Pfizer) was administered daily for $3 \mathrm{~d}$ post-op. Food and water were available ad libitum. All animals were returned to group housing the day of surgery. Coordinates were initially selected based upon established boundaries and then confirmed (Paxinos and Franklin, 2008).

\section{$q P C R$}

Mice were anesthetized with Avertin and perfused with $10 \mathrm{U} / \mathrm{ml}$ heparin (Sigma-Aldrich) in cold PBS for $\sim 6 \mathrm{~min}$. Brains then were immediately removed and placed on dry ice. When they were partially frozen, the brains were cut at bregma $-2.92 \mathrm{~mm}$ and $-5.68 \mathrm{~mm}$ to isolate midbrain tissue, which contains the dorsal raphe nucleus (DRN). With the section in a Petri dish on a cold plate, a $1.5 \mathrm{~mm}$ tissue punch was made at midline directly ventral to the third ventricle to isolate the DRN. Tissue punches were lysed and homogenized using a $1 \mathrm{ml}$ dounce homogenizer, from which RNA was isolated using a PureLink RNA Mini Kit (Ambion-Life Technologies). RNA was quantified using a NanoDrop 2000 (Thermo Scientific). Then, $244 \mathrm{ng}$ of RNA from each sample was used for reverse transcription to cDNA with a Transcriptor First Strand cDNA Synthesis Kit (Roche). Tph2 and Actb levels were quantified by qPCR using TaqMan Fast Advanced Master Mix with TaqMan Gene Expression Assays for Tph2 (Mm00557715_m1) and Actb (Mm00607939_s1) (Applied Biosystems-Life Technologies). The reactions were run in triplicate using a StepOnePlus system (Applied Biosystems) and relative expression values were calculated by StepOnePlus Software with Tph2 levels normalized to $\beta$-actin expression.

\section{Histology}

Two-weeks after surgery, mice were anesthetized with Avertin $(44 \mathrm{~mm}$ tribromoethanol, $2.5 \%$ tert-amyl alcohol, $0.02 \mathrm{ml} / \mathrm{g}$ body weight) and perfused with cold PBS for $2-5 \mathrm{~min}$, followed by cold $4 \%$ paraformaldehyde in PBS for $20 \mathrm{~min}$. The brains were removed and cryoprotected in $30 \%$ sucrose:PBS overnight. The brains of mice from the circadian study cohort used for histology of the suprachiasmatic nucleus (SCN) were removed, drop fixed in $4 \%$ paraformaldehyde in PBS overnight, and then 
cryoprotected in $30 \%$ sucrose/PBS until sectioning. With the brain frozen, coronal sections $(20 \mu \mathrm{m})$ were taken through all serotonergic nuclei and the SCN using a sliding microtome. Those sections were left floating in PBS at $4^{\circ} \mathrm{C}$ until staining. Similar sections from control and experimental mice were mounted on SuperFrost Plus slides ( Thermo Fisher Scientific) and vacuum dried. They were then permeabilized in $0.3 \%$ Triton X-100/PBS (PBS-T) and blocked in 5\% normal goat serum in PBS-T. Before blocking, antigen retrieval was performed only on slides containing sections through the SCN due to overfixation from overnight drop fixation. Slides were placed in $10 \mathrm{~mm}$ sodium citrate, microwaved at low power for $10 \mathrm{~min}$, cooled to room temperature, and washed $3 \times 5$ $\mathrm{min}$ in PBS. All slides were then incubated in primary antibody in blocking solution overnight at $4^{\circ} \mathrm{C}$, washed $6 \times 5 \mathrm{~min}$ in PBS-T, incubated in secondary antibody, and washed $6 \times 5 \mathrm{~min}$ in PBS-T. Coverslips were mounted with ProLong Gold Antifade Mountant with DAPI (Invitrogen-Life Technologies). Primary antibodies used were rabbit antiTph2 (1:500, catalog \#ABN60; Millipore), rabbit anti-5-HT (1:750, catalog \#20080; ImmunoStar), and rabbit anti-aromatic L-amino acid decarboxylase (anti-aromatic L-amino acid decarboxylase, 1:200, catalog \#CA-201 bDCrab; Protos). The secondary antibody used was goat antirabbit Alexa Fluor 594 (1:500, catalog \#A-11037; Invitrogen). Coronal brain sections were selected based upon established boundaries and regions of interest were identified using well established cytoarchitectural landmarks (Paxinos and Franklin, 2008). Sections were imaged on an Olympus Optical BX51 microscope using a SPOT RT color digital camera and SPOT Advanced software (Diagnostic Instruments). Brightness and contrast were adjusted using Adobe Photoshop. Specific numeric values for brightness and contrast adjustments were established for a single image in each experiment. Those specific adjustment values were then applied to all images of control and experimental animals within that experiment. The investigator was blinded to treatment group for all cell count analysis.

\section{HPLC}

Mice were anesthetized with Avertin and transcardially perfused with 10 $\mathrm{U} / \mathrm{ml}$ heparin (Sigma-Aldrich) in cold PBS for $\sim 6$ min to clear the brain of peripherally synthesized 5-HT present in blood. Brains were immediately removed and placed on dry ice. When they were partially frozen, the brains were placed on a Petri dish on a cold plate and cut at bregma -2.92 $\mathrm{mm}$ to separate the forebrain, which was immediately frozen on dry ice. Samples were shipped to the Neurochemistry Core of the Vanderbilt Brain Institute for processing and HPLC analysis of 5-HT and 5-HIAA levels as described previously (Lerch-Haner et al., 2008).

\section{Behavior}

All behavioral procedures occurred during the light phase of the cycle (0600:1800 h) except where noted. Littermates were used in cohorts whenever possible. Experimenters were always blinded to genotype and treatment. In all behavior experiments, the presence of Cre was controlled for to be certain that any observed effects were due specifically to the loss of 5-HT. Three separate cohorts were used for behavioral experiments: Cohort 1: open-field, elevated plus maze, and LD box; Cohort 2: home cage monitoring; and Cohort 3: circadian activity monitoring.

Open field, elevated plus maze, and LD box testing. Tph $2^{f l / f l}, T p h 2^{f l++}$, and $T p h 2^{f l-}$ male mice were injected at $6-8$ weeks of age and testing began 2 weeks after surgery in the Case Western Reserve University Rodent Behavior Core. One hour before the start of each testing day, mice were transported in their home cages to the test room to acclimate. The test order was as follows: day 1, open field; day 3 , elevated plus maze; and day 5, LD box. Equipment was cleaned thoroughly with $70 \%$ ethanol between testing of each mouse to remove odor cues. The open field apparatus consisted of a $40 \mathrm{~cm} \times 40 \mathrm{~cm}$ box in a dimly lit room. Using ANY-maze (Stoelting) video-tracking software, the area was subdivided digitally into center and outer areas. Animals were placed in the center of the open field and allowed to explore the enclosure freely for $30 \mathrm{~min}$. During this period, distance traveled and time spent in and number of entries to each area were measured. The elevated plus maze, equipped with infrared grid and video tracking system (Med Associates), was $\sim 1 \mathrm{~m}$ high and consisted of 2 open and 2 closed arms. Mice were placed in the center of the maze facing the open arm and their activity was recorded for $5 \mathrm{~min}$. The total time spent in the open and closed arms and the number of entries into each arm were measured. The LD box consisted of a large, clear, square chamber with an opening into a small, black, square chamber. The lit open chamber was illuminated with a $100 \mathrm{~W}$ light $40 \mathrm{~cm}$ above the chamber floor and the dark chamber was entirely enclosed with a solid black plastic top. Mice were placed in the open chamber facing away from the dark side and their exploration pattern was tracked for 5 min. Latency to cross over into the dark chamber, total duration in light, and number of transitions were scored.

Home cage monitoring. Mice were singly housed after surgery for 3-4 weeks before monitoring. Mice were video-recorded in their home cage for $48 \mathrm{~h}$ while maintaining their 12:12 LD schedule in the Vanderbilt Murine Neurobehavioral Laboratory. Automated video analysis was conducted by using HomeCageScan (CleverSys) to index time spent performing individual behaviors (Steele et al., 2007). Behaviors were categorized into inactive (sleep, pause, and stationary) and active (rear, stretch, hang, walk, drink, eat, jump, dig, forage, groom, twitch, arousal, awaken, chew, and sniff). "Sleep" and "pause" were defined as periods of inactivity lasting at least $2 \mathrm{~min}$ or $3 \mathrm{~s}$, respectively. "Stationary" was defined as any sequence for which there was no translational movement and no other behavior was selected. "Rear" was defined as coming up to, remaining in, or coming down from a reared position. "Hang" was defined as climbing up to, remaining in, or coming down from a hanging position on the wire bar lid. "Walk" was defined as any lateral movement over a given distance. "Eat" was defined as either in the middle of the act of eating or, starting from a noneating position, transitioning to eating posture and beginning eating. All procedures were approved by Vanderbilt University's Institutional Animal Care and Use Committee.

Circadian activity monitoring. Circadian locomotor activity was measured using overhead passive infrared motion detectors interfaced with a computerized data acquisition system (ClockLab: Coulbourn Instruments) at Kent State University. The data were collected in 1 min bins and activity onset was associated with lights-off, which was designated as zeitgeber time (ZT) 12, which was defined by the initial $6 \mathrm{~min}$ period that coincided with an intensity of activity that exceeded $10 \%$ of the maximum rate for the day and was followed by at least $60 \mathrm{~min}$ of sustained activity. Assessments of absolute activity were undertaken using data exported from the ClockLab data acquisition system. An activity count represented an individual event registered by an overhead infrared sensor. The threshold for the onset of a bout of activity was a 5 min period with an activity rate of 1 activity count/min and the bout ended when the activity rate dropped below 1 count $/ \mathrm{min}$. Actograms are double plotted so that $48 \mathrm{~h}$ are shown for each horizontal trace and each day of recording is presented both to the right and beneath that of the preceding day. All procedures were approved by Kent State University's Institutional Animal Care and Use Committee.

\section{Data analysis}

Statistical tests were performed as indicated in the text. All tests were performed in GraphPad Prism, Version 6.07 for Windows or SPSS Statistics for Windows, Version 23.0. Datasets with non-normal distributions were transformed as indicated or nonparametric tests were used. Datasets with unequal variances were transformed as indicated or Welch's correction was applied after Student's $t$ tests. All Student's $t$ tests were two-tailed and unpaired. Datasets evaluated by two-way repeatedmeasures (RM) ANOVA were assessed for violations of sphericity and Geisser-Greenhouse-corrected $p$-values are reported where indicated. All two-way RM-ANOVA tests were followed by post hoc testing with Sidak's correction for multiple comparisons. For all statistical tests, $p<$ 0.05 was considered statistically significant and $p$-values are indicated in the figures as follows: ${ }^{\star} p<0.05,{ }^{* *} p<0.01,{ }^{* * *} p<0.001$, and ${ }^{* * * *} p<$ 0.0001 . Values are reported as mean \pm SEM unless otherwise indicated.

\section{Results}

\section{AAV-Cre injection of $T p h 2^{f l f l}$ and $T p h 2^{f l /-}$ mice targets brain 5-HT synthesis}

Tph2 was targeted using the Cre-loxP system with $T p h 2^{\mathrm{fl}}$ mice, in which exon V of Tph2 is flanked by loxP sites (Kim et al., 2014). 
A

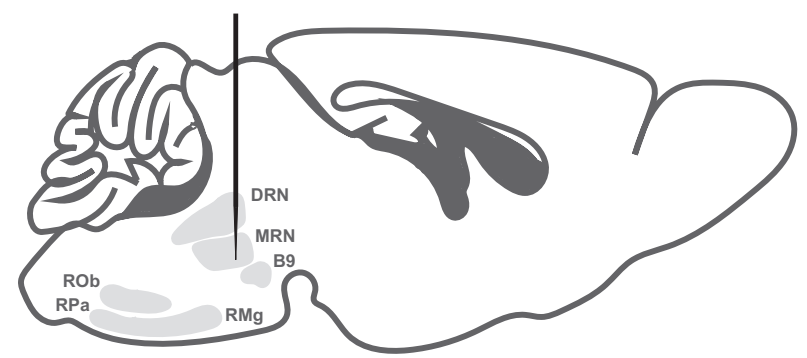

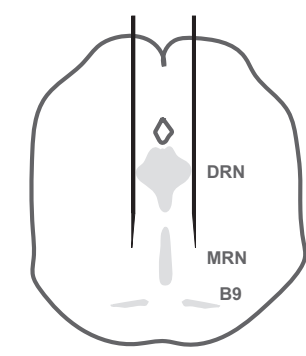

\section{Coordinates}

$x= \pm 0.5 \mathrm{~mm}$

$y=-4.2 \mathrm{~mm}$

$\mathrm{z}=-4.0 \mathrm{~mm}$
B i

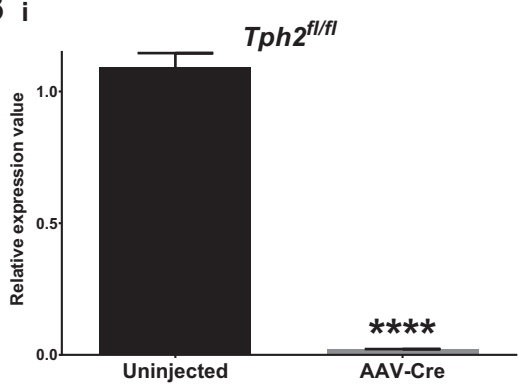

ii

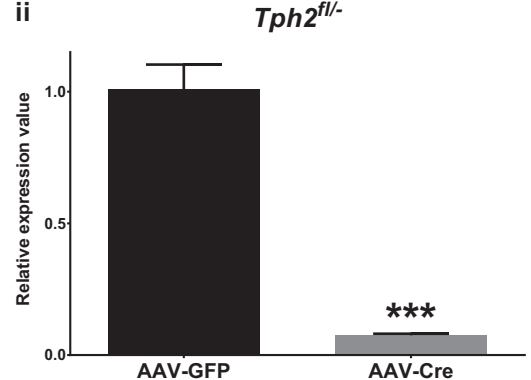

Figure 1. AAV-Cre injection into the midbrain/pons of $T p h 2^{f / f f}$ and $T p h 2^{f / /}$ mice depletes $T p h 2 m R N A . A$, Schematic of viral stereotaxic injections into the midbrain/pons. Bi, $q P C R$ evaluation of Tph2 mRNA levels in DRN punches of uninjected control and AAV-Cre-injected Tph $2^{f / f l}$ mice $(n=3-4)$. Bii, qPCR evaluation of Tph2 mRNA levels in dorsal raphe punches of AAV-GFP- and AAV-Cre-injected $T p h 2^{f /-}$ mice $(n=4-5)$. MRN, median raphe nucleus; RMg, raphe magnus; ROb, raphe obscurus; RPa, raphe pallidus.

Cre was expressed in $T p h 2^{\mathrm{fl}}$ mice through bilateral stereotaxic injections of AAV-Cre into the midbrain and pons, where the anterior raphe nuclei are located (Fig. 1A). These nuclei comprise the $\mathrm{B} 6$ and $\mathrm{B} 7$ groups (DRN), B5 and $\mathrm{B} 8$ groups (median raphe nucleus, caudal linear nucleus, and apical subdivision of the interpeduncular nucleus), and the B9 group (medial lemniscus, lateral subdivision of the interpeduncular nucleus, and pontomesencephalic reticular formation). We explored two different experimental strategies using either $T p h 2^{f l / f l}$ or $T p h 2^{f l /-}$ mice. In the first experiment, the control and experimental groups consisted of $T p h 2^{f l / f l}$ mice that were not injected or injected with AAV-Cre, respectively. Three-weeks after injection, Tph 2 mRNA levels were reduced by $98.08 \%$ in DRN punches of AAV-Creinjected $T p h 2^{f l / f l}$ mice relative to controls $\left(t\right.$ test, $t_{(5)}=49.86, p<$ 0.0001 , log-transformed data, $n=3-4$; Fig. $1 B i)$. Using Tph $2^{f l f l}$ mice would allow for a very efficient breeding strategy and maximum flexibility in assembling cohorts for experiments. However, we were also interested in testing this protocol in $T p h 2^{f l-}$ mice because they could be used in future experiments in combination with AAV-Cre-injected Tph $2^{f l /+}$ mice to control for the presence of Cre. In the second experiment, $T p h 2^{f l-}$ mice were injected with AAV-GFP or AAV-Cre. Tph2 mRNA levels were reduced by $92.53 \%$ in DRN punches of AAV-Cre-injected $T p h 2^{f l /-}$ mice compared with AAV-GFP-injected controls ( $t$ test, $t_{(7)}=21.08, p<0.0001$, log-transformed data, $n=4-5$; Fig. 1Bii). These data demonstrate that AAV-Cre injection into the midbrain/pons of $T p h 2^{f l / f l}$ and $T p h 2^{f l-}$ mice results in nearcomplete loss of Tph 2 mRNA in the DRN.

We also determined the efficiency of Tph2 elimination at the protein level. Two weeks after AAV-Cre injection, Tph2 immunoreactivity in $T p h 2^{f l / f l}$ mice was abolished in nearly all cell bodies of the anterior raphe nuclei. Tph2 expression in the caudal nuclei, which comprises the B1-B3 groups (raphe pallidus, raphe obscurus, raphe magnus, and lateral paragigantocellular reticular nucleus), was not significantly altered (Fig. 2Ai). Specifically, the number of Tph2-immunopositive neurons was decreased by $99 \%$ in the B6 and B7 groups $\left(t\right.$ test, $t_{(6)}=28.09, p<0.0001$, square-root-transformed data, $n=4)$, by $92 \%$ in the B5 and B8 groups ( $t$ test, $t_{(6)}=15.45, p<0.0001, n=4$ ), and by $89 \%$ in the B9 group ( $t$ test, $t_{(6)}=80.35, p<0.0001$, squared transformed data, $n=4$; Fig. 2Aii). The number of Tph2-immunopositive neurons in the B1-B3 groups was not significantly different $(t$ test, $t_{(4)}=0.2675, p=0.8023, n=3$; Fig. 2Aii). AAV-Cre injection of $T p h 2^{f l-}$ mice resulted in equally robust eliminations of Tph2 expression in the B5-B9 groups, with intact expression in the B1-B3 groups at 2 weeks after injection (Fig. $2 B$ ). This was paralleled by a near-total loss of 5-HT immunoreactivity in the B5-B9 groups and sparing of the caudal nuclei at 2 weeks after injection (Fig. 2B). The expression of aromatic L-amino acid decarboxylase, a second enzyme required for 5-HT synthesis, was not altered, indicating that the loss of Tph2 and 5-HT immunoreactivity was not due to 5 -HT neuron death (Fig. $2 B$ ).

To quantitate the decrease in 5-HT levels, HPLC was performed on whole forebrain tissue. AAV-Cre injection of Tph $2^{f l / f l}$ mice resulted in a $97 \%$ decrease in forebrain 5-HT $(t$ test with Welch's, $t_{(3.000)}=7.715, p=0.0045, \mathrm{Y}^{2}$-transformed data) and a $99 \%$ decrease in 5-HIAA ( $t$ test with Welch's, $t_{(3.286)}=20.95, p=$ 0.0001 , square-root-transformed data), the main metabolite of 5-HT, compared with uninjected controls at 6 weeks after injection $(n=4-5$; Fig. 3Ai). To determine whether a comparable decrease in 5-HT was reached at an earlier time point after injection, we evaluated $T p h 2^{f l f l}$ mice at 2 weeks after injection, which showed similar reductions in forebrain 5-HT (95\%, $t$ test with Welch's, $\left.t_{(2.096)}=10.17, p=0.0081\right)$ and 5 -HIAA (98\%, $t$ test with Welch's, $\left.t_{(2.034)}=13.50, p=0.0051\right)$ relative to AAV-GFPinjected controls $(n=3-4$; Fig. 3Aii). Similarly, AAV-Cre injection in $T p h 2^{f l-}$ mice resulted in a 93\% decrease in forebrain 5 -HT ( $t$ test, $t_{(4)}=30.02, p<0.0001$ ) and a 95\% decrease in 5 -HIAA ( $t$ test, $t_{(4)}=23.87, p<0.0001$, square-root-transformed data, compared with AAV-GFP-injected controls at 2 weeks after injection, $n=3$; Fig. 3B). Two weeks after injection, the levels of dopamine (DA) and norepinephrine (NE) were not statistically different compared with control (DA: $T p h 2^{f l f f l}, t_{(5)}=0.3144, p=$ $0.7659 ; T p h 2^{f l-}, t_{(4)}=1.415, p=0.2299 ; \mathrm{NE}: T p h 2^{f l / f l}$ : 
A

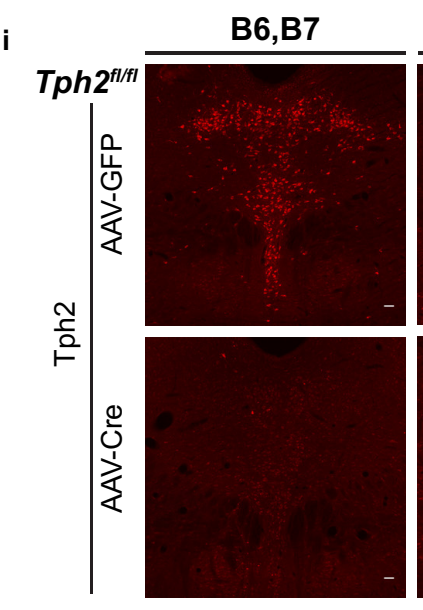

ii

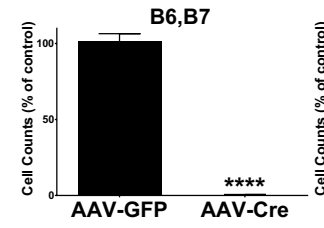

B5,B8
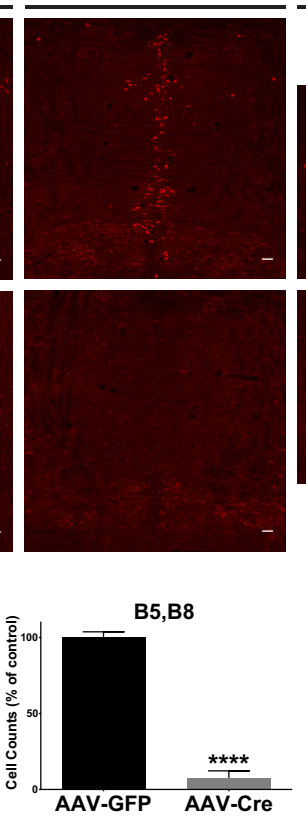

B9
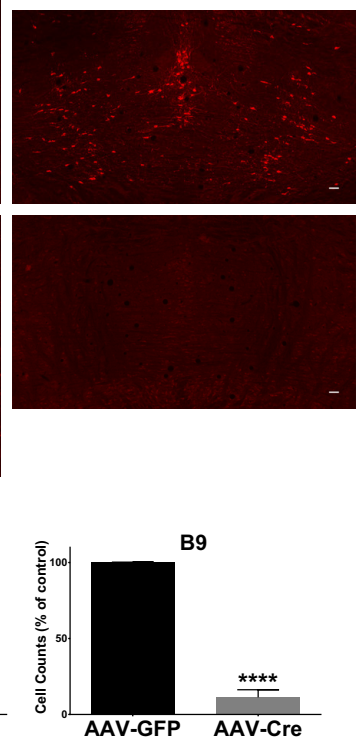

B1-3
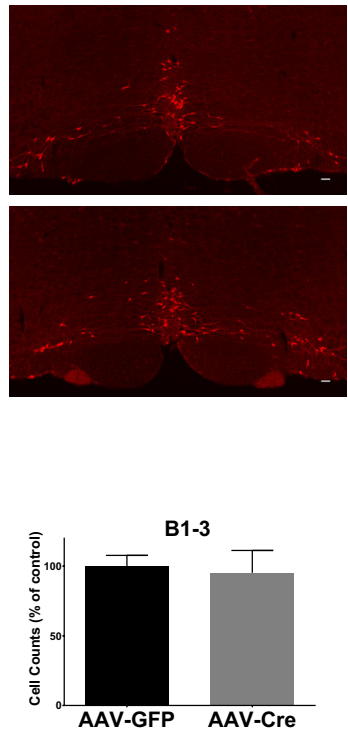

B
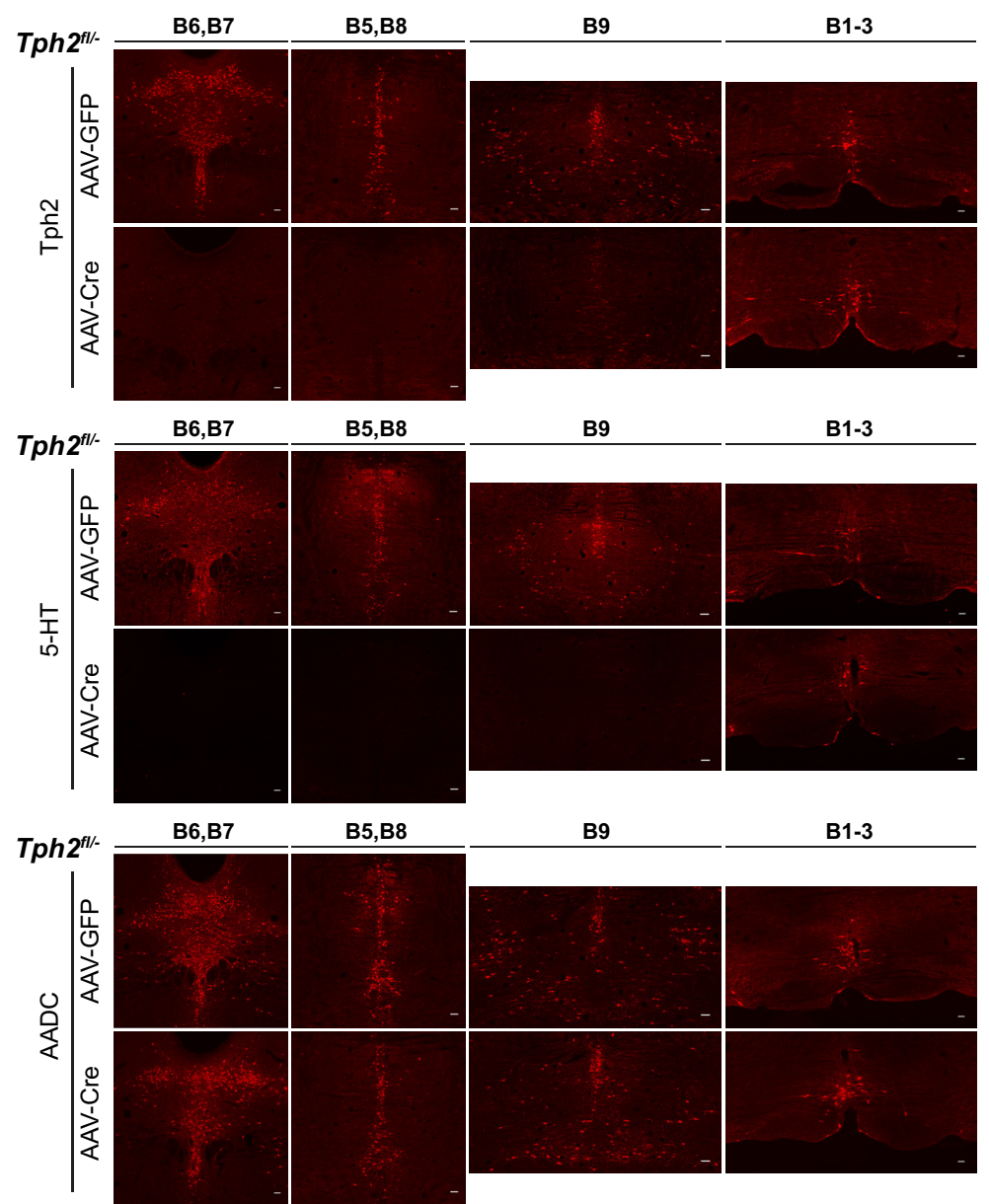

Figure 2. AAV-Cre-mediated targeting of Tph2 expression in anterior raphe 5-HT neurons. Ai, Immunofluorescence of Tph2 expression in the raphe nuclei of AAV-GFP- and AAV-Cre-injected Tph $2^{f / f l}$ mice. Aii, Counts of Tph2-immunopositive neurons in AAV-GFP- and AAV-Cre-injected Tph2 $2^{f / / f l}$ mice: groups B6 and B7 $(n=4), B 5$ and B8 $(n=4), B 9(n=4)$, and B1-B3 ( $\left.n=3\right)$. B, Immunofluorescence of Tph2, 5-HT, and AADC in the raphe nuclei of AAV-GFP- and AAV-Cre-injected Tph $2^{f / /}$ - mice. 


\section{A $T p h 2^{t / f t}$}

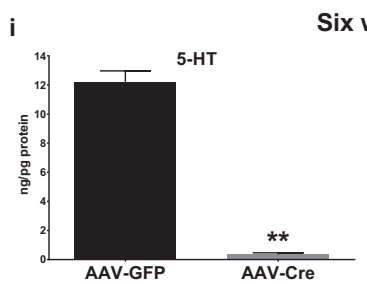

Six weeks

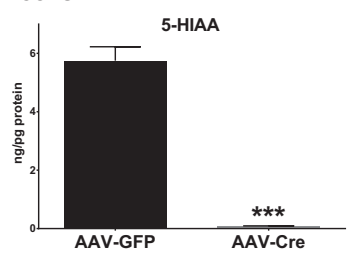

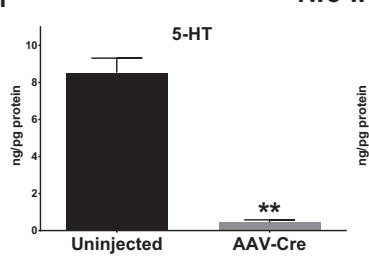

Two weeks

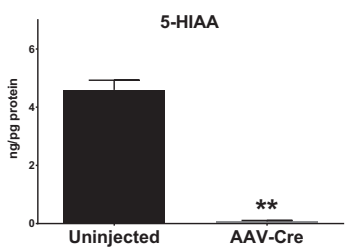

B $T p h 2^{\text {th- }}$
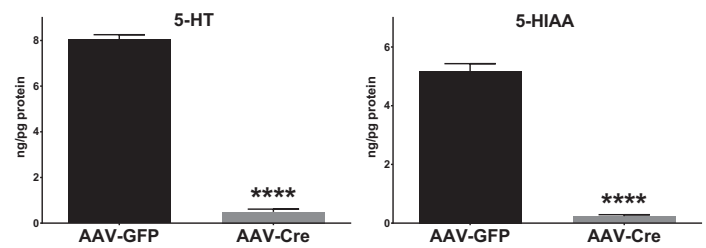

Figure 3. Near-complete elimination of 5-HT after AAV-Cre injection of $T p h 2^{f / f f l}$ and $T p h 2^{f /-}$ mice. Ai, HPLC analysis of 5-HT and 5-HIAA levels in forebrain tissue of $T p h 2^{f / f f l}$ mice $(n=4-5)$. Mice were injected with AAV-Cre or AAV-GFP and tissue was harvested 6 weeks after injection. Aii, HPLC analysis of 5-HT and 5-HIAA levels in forebrain tissue of Tph ${ }^{f / f l}$ mice $(n=3-4)$. Mice were injected with AAV-Cre or left uninjected and tissue was harvested 2 weeks after injection. $\boldsymbol{B}$, HPLC analysis of 5-HT and 5-HIAA levels in forebrain tissue of Tph $2^{f / /}$ mice $(n=3)$. Mice were injected with AAV-GFP and AAV-Cre and tissue was harvested 2 weeks after injection.

$t_{(5)}=1.740, p=0.1424$, squared data transformed; Tph $2^{f l-}$ : $t_{(2.058)}=2.250, p=0.1498$, log-transformed data). At postinjection time points beyond 2 weeks, DA levels remained unchanged, but NE levels in Tph2-CKO mice were variable relative to control levels. This raises the possibility that long-term deficiency of adult brain 5-HT synthesis may have secondary effects on the stability of other monoamine systems. It will also be interesting to determine whether the primary loss of 5-HT synthesis, which would be expected to alter the activity of targeted 5-HT neurons, affects indirectly the release of other cotransmitters normally released from those neurons.

\section{Adult brain 5-HT deficiency does not affect anxiety-like behaviors}

Having established an efficient method for near-complete elimination of 5-HT synthesis in the anterior raphe nuclei, we next investigated the behavioral impact of this specific transmitter deficit. Many studies over the past several decades have investigated the role of 5-HT in regulating anxiety-like behaviors using a number of knock-out mouse models and pharmacologic approaches that perturb the 5-HT system (Fernandez and Gaspar, 2012; Lesch et al., 2012; Mosienko et al., 2015). However, these studies produced disparate results, with some indicating a role for 5-HT in these behaviors and others demonstrating a lack thereof (Hendricks et al., 2003; Savelieva et al., 2008; Schaefer et al., 2009; Liu et al., 2010; Angoa-Pérez et al., 2012; Mosienko et al., 2012; Gutknecht et al., 2015; Johnson et al., 2015). Therefore, we initially focused our investigations on anxiety-like behaviors and tested whether the loss of adult brain 5-HT affected those behaviors. Male mice were injected at $6-8$ weeks of age and subjected to open-field, elevated plus maze, and LD box testing at 2 weeks after injection. The control group (Tph2-CON) consisted of AAV-GFPinjected $T p h 2^{f l / f l}$ mice and AAV-Cre-injected Tph $2^{f l /+}$ mice and the experimental group (Tph2-CKO) consisted of AAV-Creinjected $T p h 2^{f l-}$ and $T p h 2^{f l f l}$ mice. There were no significant differences in any open-field test measures (distance traveled, center entries, center time, outer entries, and outer time) within the control group between AAV-Cre-injected and AAV-GFP- injected mice (2-way ANOVA; virus, $F_{(1,165)}=0.1148, p=$ 0.7352 ; open-field measure, $F_{(4,165)}=862.0, p<0.0001$; virus $\times$ open-field measure: $\left.F_{(4,165)}=1.761, p=0.1391\right)$.

In the open-field test, Tph2-CKO mice showed no differences relative to $T p h 2-C O N$ mice in time spent in the center area ( $t$ test, $t_{(56)}=1.098, p=0.2767, \log$-transformed data) or time spent in the outer area (Mann-Whitney $U$ test $=323, p=0.1384, n=$ 27-31; Fig. 4A). In the elevated plus maze, no differences in the time spent in the open arms $\left(t\right.$ test, $\left.t_{(19)}=1.063, p=0.3010\right)$ or closed arms ( $t$ test, $\left.t_{(19)}=0.6215, p=0.5417\right)$ or in the number of entries to the open arms ( $t$ test, $\left.t_{(19)}=0.4228, p=0.6772\right)$ or closed arms ( $t$ test, $\left.t_{(19)}=0.01446, p=0.9885\right)$ were detected in Tph2-CKO mice compared with Tph2-CON mice $(n=10-11$; Fig. $4 B$ ). Finally, in the LD box test, Tph2-CKO mice spent a similar amount of time in the light area $\left(t\right.$ test, $t_{(19)}=0.1486, p=$ 0.8834 , square-root-transformed data) and had a similar number of transitions between the light and dark areas as Tph2-CON mice ( $t$ test, $t_{(19)}=1.182, p=0.2519, n=10-11$; Fig. $\left.4 C\right)$. Therefore, our results indicate that a severe deficiency of adult 5-HT synthesis in the anterior raphe nuclei does not lead to an anxiety-like phenotype. Intriguingly, the discrepancy between $T p h 2^{-1-}$ and Tph2-CKO mice in measures of anxiety may result from effects of 5 -HT loss on the development of anxiety circuits versus a specific lack of serotonergic transmission in adulthood (Mosienko et al., 2012). In addition, the anxiety phenotypes associated with fetal and adult Pet- 1 targeting may result from the multiple gene expression defects in 5-HT neurons in these mice (Hendricks et al., 2003; Liu et al., 2010; Wyler et al., 2016).

\section{Adult brain 5-HT deficiency increases locomotor activity in a novel environment}

Interestingly, in the same open-field test, Tph2-CKO mice exhibited increased locomotor activity, as indicated by an increase in the total distance traveled $\left(t\right.$ test, $t_{(56)}=4.764, p<0.0001$, logtransformed data; Fig. $4 \mathrm{Di})$. The number of entries to the center ( $t$ test, $t_{(56)}=2.678, p=0.0097$, square-root-transformed data) and outer areas $\left(t\right.$ test, $\left.t_{(56)}=2.921, p=0.0050\right)$ were also increased in Tph2-CKO mice (Fig. 4Dii). In addition, the activity 
A

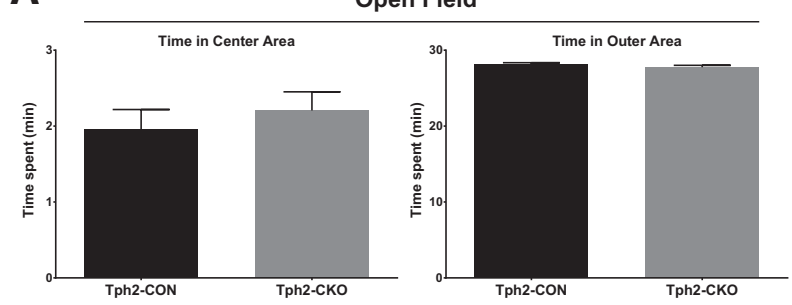

C

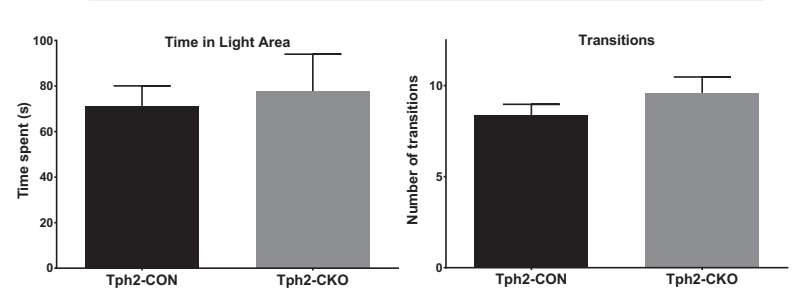

B Elevated-Plus Maze
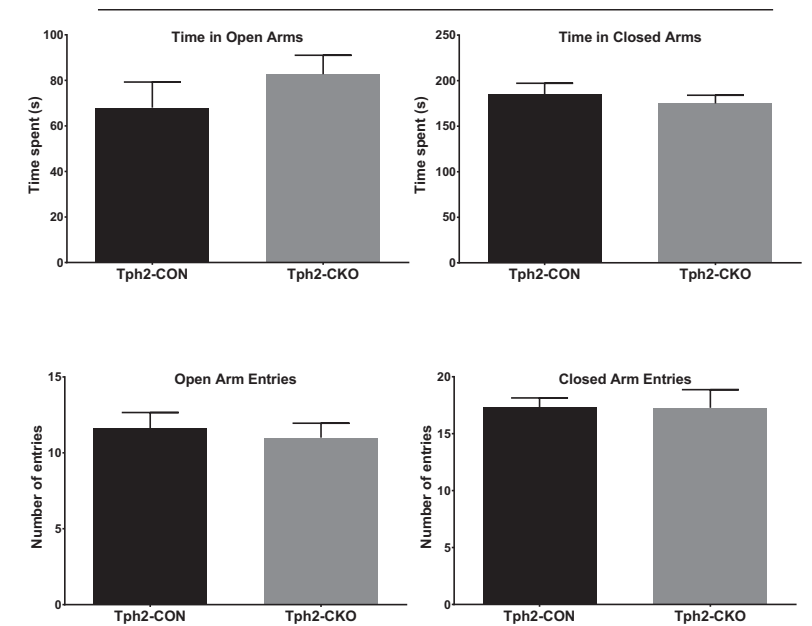

D i

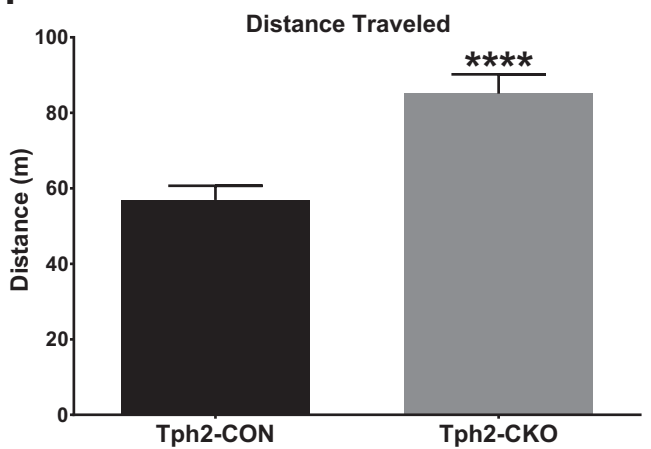

Tph2-CON

iii

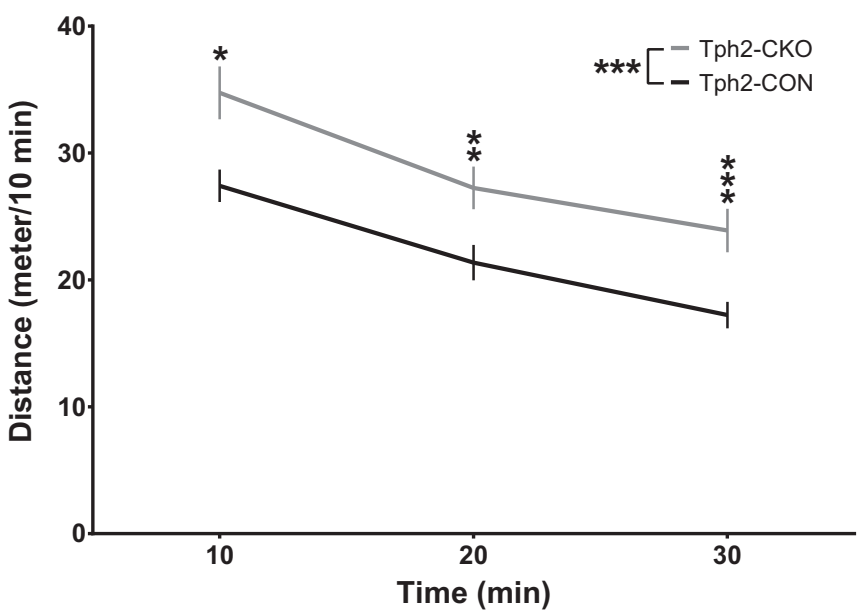

ii
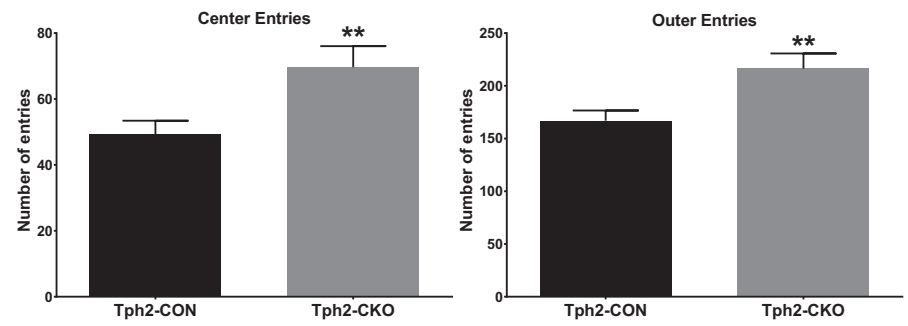

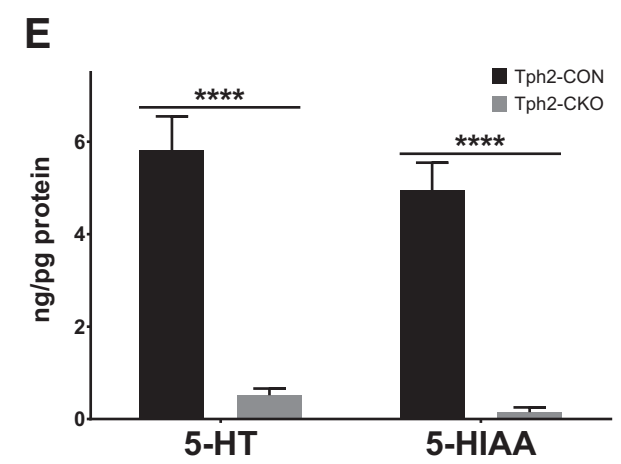

Figure 4. Adult brain 5-HT deficiency does not affect anxiety-like behaviors, but increases locomotor activity in a novel environment. $\boldsymbol{A}, 0$ pen-field testing: time in center and outer areas ( $n=$ 27-31). $\boldsymbol{B}$, Elevated plus maze testing: open arm time, closed arm time, open arm entries, and closed arm entries ( $n=10-11)$. $\boldsymbol{C}$, Light/dark box testing: time in light area and number of transitions $(n=10-11)$. D, Same open-field test as in $\boldsymbol{A}$ for total distance traveled (Di), number of entries to center and outer areas (Dii), and distance traveled over time in the open-field test ( $\boldsymbol{D i i i})$. $\boldsymbol{E}$, HPLC analysis of 5-HT and 5-HIAA levels in forebrain tissue of Tph2-CON and Tph2-CKO mice $(n=12-20)$.

levels of Tph2-CKO mice were increased at the start of the test and continued to be significantly higher than Tph2-CON mice for the duration of the 30 min test (2-way RM-ANOVA; 5-HT depletion: $F_{(1,56)}=12.19, p=0.0009$; time: $F_{(2,112)}=98.38, p<0.0001$; 5-HT depletion $\times$ time: $F_{(2,112)}=1.128, p=0.3273$; post hoc testing with Sidak's correction, log-transformed data; Fig. 4Diii).
After the completion of behavioral testing, near-complete elimination of 5-HT (Mann-Whitney $U$ test $=0, p<0.0001$ ) and 5-HIAA (Mann-Whitney $U$ test $=0, p<0.0001$ ) were confirmed in the Tph2-CKO mice compared with the Tph2-CON mice (Fig. 4E).

Together, these results indicate that a deficiency of adult brain 5-HT synthesis increases locomotor activity. However, to 
confirm definitively that the hyperactivity was not due to the novel environment, we proceeded to measure the activity of Tph2-CON and Tph2-CKO mice in their familiar home cages.

\section{Deficiency of 5-HT synthesis in the adult brain increases home cage activity}

In an independent cohort, we performed a home cage monitoring study in which control and experimental groups were monitored continuously for $48 \mathrm{~h}$. Male mice were injected at 13 weeks of age, singly housed, and home cage monitoring began 3-4 weeks after injection. The experimental group (Tph2-CKO) consisted of 14 AAV-Cre-injected $T p h 2^{f /-}$ mice and the control group (Tph2$C O N$ ) consisted of nine AAV-Cre-injected Tph $2^{f l /+}$ mice, two AAVCre-injected $T p h 2^{+/-}$mice, and five AAV-GFP-injected $T p h 2^{\mathrm{f} / \mathrm{fl}}$ mice.

Initial analysis of the results revealed significant differences in the time spent per day in several specific behaviors. Tph2-CKO mice spent significantly less time in inactive behaviors such as sleep ( $t$ test, $\left.t_{(28)}=2.682, p=0.0121\right)$ and pause $\left(t\right.$ test, $t_{(28)}=$ $2.254, p=0.0322$, square-root-transformed data), which are defined by the HomeCageScan software (Cleversys) as periods of inactivity lasting at least $2 \mathrm{~min}$ or $3 \mathrm{~s}$, respectively (Fig. $5 \mathrm{Ai}, \mathrm{Bi}$ ). Conversely, they spent more time in active behaviors such as rearing $\left(t\right.$ test, $\left.t_{(28)}=2.074, p=0.0474\right)$ and walking $(t$ test with Welch's correction, $t_{(18.99)}=2.763, p=0.0124, \log$-transformed data) compared with Tph2-CON mice (Fig. 5Ci,Di). These results suggested an overall increase in activity in a familiar environment relative to $T p h 2-C O N$ mice.

To further investigate home cage behavior of Tph2-CKO mice, we examined the time spent in several active and inactive behaviors during light and dark phases. In each behavior, there was a significant main effect of 5-HT depletion, suggesting that the loss of brain 5-HT affected activity during both the dark and light periods. However, there were notable temporal differences between Tph2-CON and Tph2-CKO mice among various inactive and active behaviors. Compared with Tph2-CON mice, the time Tph2-CKO mice spent in sleep was decreased only during the light period (2-way RM-ANOVA; 5-HT depletion: $F_{(1,28)}=$ $6.643, p=0.0155$; time: $F_{(1,28)}=110.6, p<0.0001 ; 5$-HT depletion $\times$ time: $F_{(1,28)}=2.564, p=0.1206$; post hoc testing with Sidak's correction, square-root-transformed data; Fig. 5Aii), whereas the time spent in pause was decreased only during the dark period (2-way RM-ANOVA; 5-HT depletion: $F_{(1,28)}=$ $4.568, p=0.0415$; time: $F_{(1,28)}=0.3463, p=0.5610 ; 5-\mathrm{HT}$ depletion $\times$ time: $F_{(1,28)}=3.297, p=0.0801$; post hoc testing with Sidak's correction, square-root-transformed data; Fig. 5Bii). The time that $T p h 2-C K O$ mice spent rearing (two-way RM-ANOVA; 5-HT depletion: $F_{(1,28)}=4.682, p=0.0392$; time: $F_{(1,28)}=68.44$, $p<0.0001$; 5-HT depletion $\times$ time: $F_{(1,28)}=3.806, p=0.0611$; post hoc testing with Sidak's correction, log-transformed data; Fig. 5Cii), walking (two-way RM-ANOVA; 5-HT depletion: $F_{(1,28)}=9.218, p=0.0051$; time: $F_{(1,28)}=163.2, p<0.0001$; 5-HT depletion $\times$ time: $F_{(1,28)}=4.170, p=0.0507$; post hoc testing with Sidak's correction, square-root-transformed data; Fig. 5Dii), hanging (two-way RM-ANOVA; 5-HT depletion: $F_{(1,28)}=3.859, p=0.0595$; time: $F_{(1,28)}=241.4, p<0.0001$; 5-HT depletion $\times$ time: $F_{(1,28)}=9.952, p=0.0038$; post hoc testing with Sidak's correction, log-transformed data; Fig. 5E), and eating (two-way RM-ANOVA; 5-HT depletion: $F_{(1,28)}=$ $2.180, p=0.1510$; time: $F_{(1,28)}=284.6, p<0.0001 ; 5$-HT depletion $\times$ time: $F_{(1,28)}=5.483, p=0.0265$; post hoc testing with Sidak's correction, square-root-transformed data; Fig. $5 F$ ) were all significantly increased during the light period. To assess over- all activity levels, individual behaviors were grouped into active and inactive behaviors (see Materials and Methods). Tph2-CKO mice spent significantly more time in active behaviors per day $(t$ test, $t_{(28)}=4.009, p=0.0004$, log-transformed data; Fig. 5Gi). Specifically, the time spent in active behaviors was significantly increased during both the light and dark periods (2-way RMANOVA; 5-HT depletion: $F_{(1,28)}=16.28, p=0.0004$; time: $F_{(1,28)}=163.0, p<0.0001 ; 5-\mathrm{HT}$ depletion $\times$ time: $F_{(1,28)}=$ $3.217, p=0.0837$; post hoc testing with Sidak's correction, square-root-transformed data; Fig. 5 Gii). Together, these results indicated that Tph2-CKO mice may be more active in the dark period, when mice are naturally active. However, this analysis also showed that Tph2-CKO mice were significantly more active than Tph2-CON mice in the light period, when mice naturally sleep, which suggests that there may be a disruption in sleep and circadian rhythms.

After completion of behavioral testing, near-total elimination of 5-HT ( $t$ test, $\left.t_{(25)}=18.67, p<0.0001\right)$ and 5-HIAA ( $t$ test with Welch's correction, $\left.t_{(17.66)}=17.72, p<0.0001\right)$ were confirmed in the Tph2-CKO mice compared with Tph2-CON mice (Fig. 5H).

\section{Deficient adult brain 5-HT synthesis disrupts daily circadian behavior patterns and induces hyperactivity}

To determine whether adult 5-HT synthesis is required to maintain normal circadian behavioral patterns, we performed a circadian locomotor activity study in an independent cohort. Tph $2^{f l+}$ $(T p h 2-C O N)$ and Tph $2^{f l-}(T p h 2-C K O)$ mice received AAV-Cre injection at 7-9 weeks of age and were individually housed 1 week after injection in a 12:12 LD cycle $(n=11-12)$. After an additional 2-week period of acclimation to the monitoring chambers, we collected activity data for $11 \mathrm{~d}$ using infrared motion sensors.

As seen in the representative actograms, Tph2-CKO mice displayed numerous abnormalities in their daily activity patterns compared with Tph2-CON mice (Fig. 6A). Tph2-CKO mice entrain to a $\mathrm{LD}$ cycle, as indicated by their normal period length (Tph2-CON $24.01 \pm 0.01677$ vs Tph2-CKO $24.02 \pm 0.03464 \mathrm{~h}, t$ test with Welch's correction, $\left.t_{(12.47)}=0.9046, p=0.3828\right)$. However, Tph2-CKO mice showed an advance in the onset $(t$ test, $t_{(21)}=2.396, p=0.0260 ;$ Fig. $\left.6 \mathrm{Bi}\right)$ and a delay in the offset $(t$ test, $t_{(21)}=5.688, p<0.0001$; Fig. 6 Bii) of their daily activity, which lengthened their active phase (alpha) by $>2 \mathrm{~h}\left(t\right.$ test, $t_{(21)}=6.072$, $p<0.0001$; Fig. 6 Biii). Activity profile data, normalized to total activity levels, revealed that the extension of the alpha phase was independent of any differences in absolute activity and due to a redistribution of activity throughout the $24 \mathrm{~h}$ period (2-way RMANOVA; 5-HT depletion: $F_{(1,21)}=26.813, p<0.0001$; time: $F_{(5.504,115.579)}=105.672, p<0.0001 ; 5-\mathrm{HT}$ depletion $\times$ time: $F_{(5.504,115.579)}=8.984, p<0.0001$; post hoc testing with Sidak's correction, square-root-transformed data; Fig. $6 C$ ). This was reflected in a similar increase in the time spent active by Tph2-CKO mice during the light period (2-way RM-ANOVA; 5-HT depletion: $F_{(1,21)}=26.61, p<0.0001$; time: $F_{(1,21)}=328.8, p<0.0001$; 5-HT depletion $\times$ time: $F_{(1,21)}=0.1433, p=0.7089$; post hoc testing with Sidak's correction; Fig. $6 D$ ). Together, these data demonstrate significant disruption of circadian activity patterns under normal LD conditions after loss of adult brain 5-HT synthesis.

Although these analyses showed differences in the pattern of circadian activity in Tph2-CKO mice, they did not assess absolute activity levels. To evaluate absolute activity, we analyzed activity count data for each mouse from the circadian study dataset, which revealed that total daily activity was significantly increased in Tph2-CKO mice (Tph2-CON $1267 \pm 720.5$ vs Tph2-CKO 

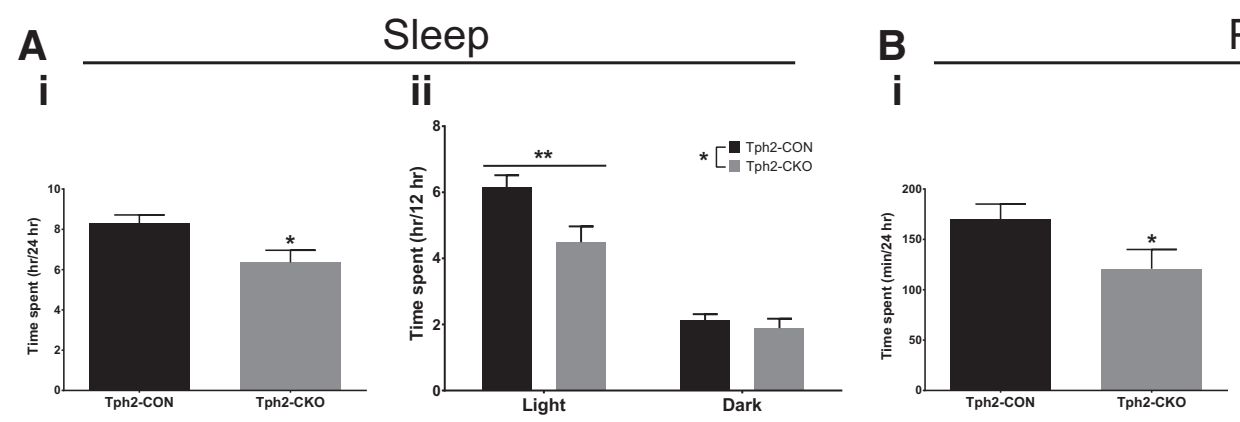

Pause

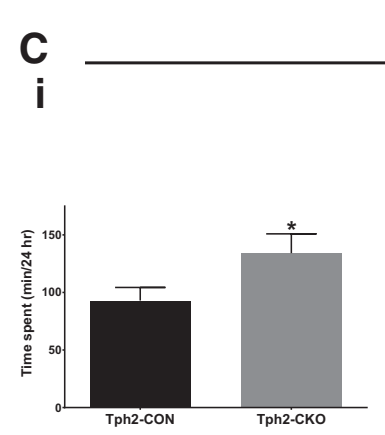

Rear
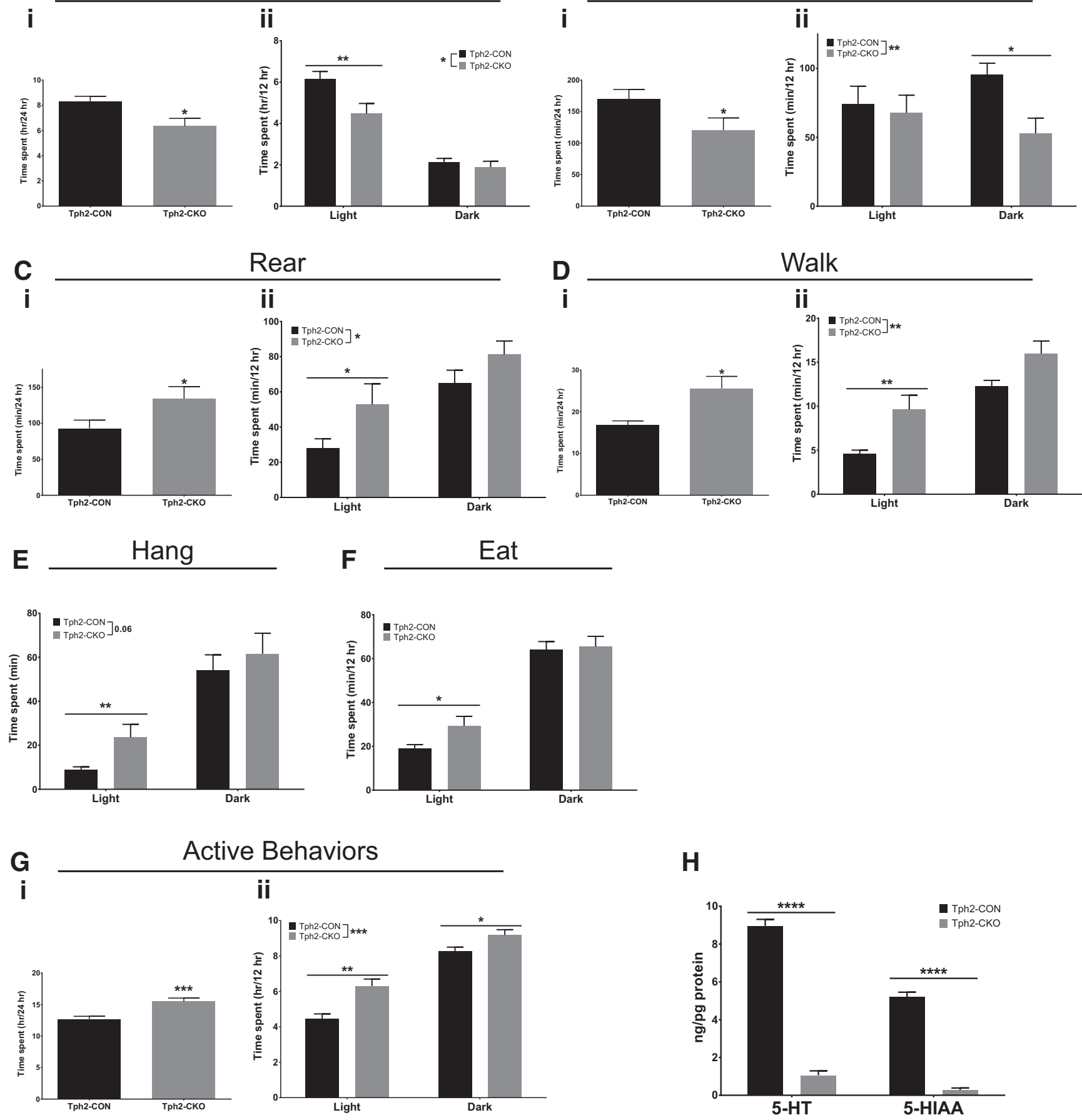

Figure 5. Adult brain 5-HT deficiency increases home cage activity. $\boldsymbol{A}$, Sleep: time spent per day (Ai), time spent in light versus dark (Aii) $(n=14-16) . \boldsymbol{B}$, Pause: time spent per day (Bi), time spent in light versus dark (Bii) $(n=14-16)$. C, Rear: time spent per day (Ci), and time spent in light versus dark (Cii) $(n=14-16)$. D. Walk: time spent per day (Di), and time spent in light versus $\operatorname{dark}(\boldsymbol{D i i i})(n=14-16)$. $\boldsymbol{E}$, Hang: time spent in light versus dark $(n=14-16)$. $\boldsymbol{F}$, Eat: time spent in light versus dark $(n=14-16)$. $\boldsymbol{G}$, Home cage monitoring behaviors were grouped into active and inactive behaviors. Gi, Total time spent in active behaviors per day. Gii, Time spent in active behaviors in the light and dark periods $(n=14-16)$. $\boldsymbol{H}$, HPLC analysis of 5 -HT and 5 -HIAA levels in forebrain tissue of Tph2-CON and Tph2-CKO mice $(n=13-14)$.

$2847 \pm 1302$ activity counts/d, $t$ test, $t_{(21)}=3.793, p=0.0011$ data log transformed). Furthermore, the percentage increase in total daily activity (125\%, Tph2-CON $1267 \pm 720.5$ vs Tph2CKO $2847 \pm 1302$ counts/d, $t$ test, $\left.t_{(21)}=3.793, p=0011\right)$ was almost double the percentage increase in time spent active $(68 \%$, Tph2-CON 7.943 \pm 2.454 vs Tph2-CKO $13.36 \pm 2.587 \mathrm{~min}, t$ test, $t_{(21)}=5.157, p<0.0001$ ), suggesting an absolute increase in activity. Tph2-CKO mice also had significantly increased activity counts in both the light and dark periods compared with Tph2CON mice (2-way RM-ANOVA; 5-HT depletion, $F_{(1,21)}=18.83$, $p=0.0003$; time, $F_{(1,21)}=172.2, p<0.0001 ; 5$-HT depletion $\times$ time: $F_{(1,21)}=0.7688, p=0.3905$, post hoc testing with Sidak's correction, square-root-transformed data; Fig. $7 A$ ). To determine whether absolute activity of Tph2-CKO mice was increased uniformly across the entire $24 \mathrm{~h}$ period, we plotted the average activity profiles for Tph2-CON and Tph2-CKO mice (Fig. 7B). 
A

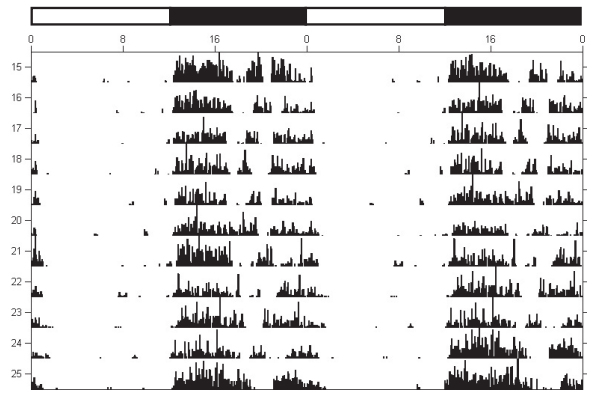

Tph2-CKO

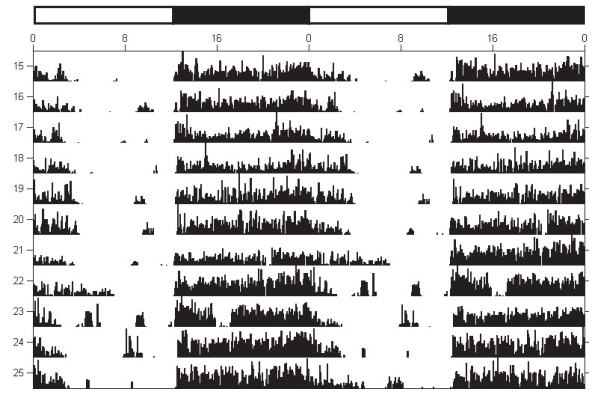

B

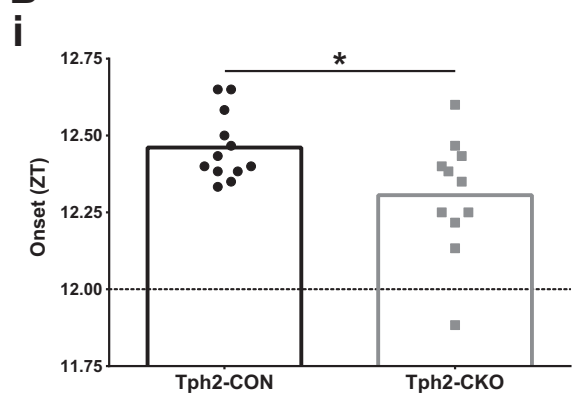

ii

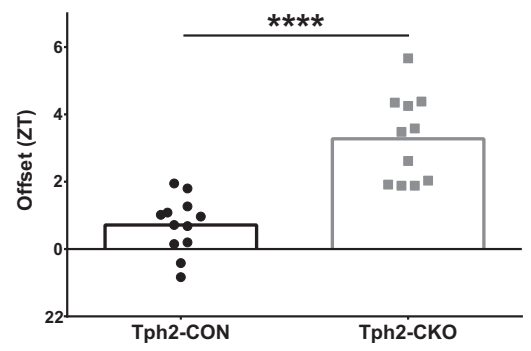

iii

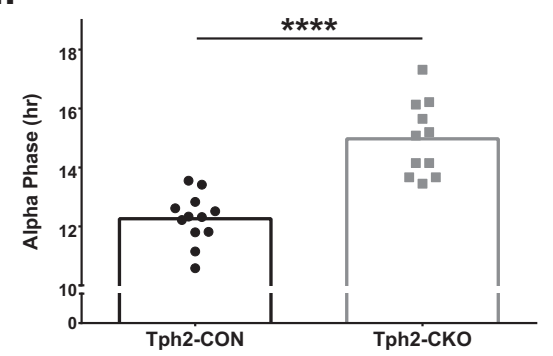

C

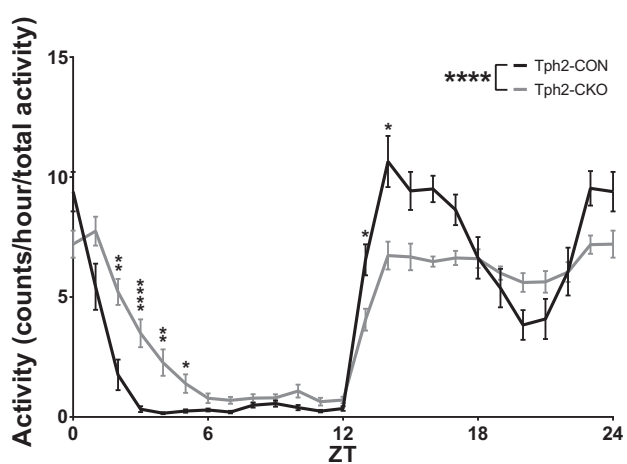

D

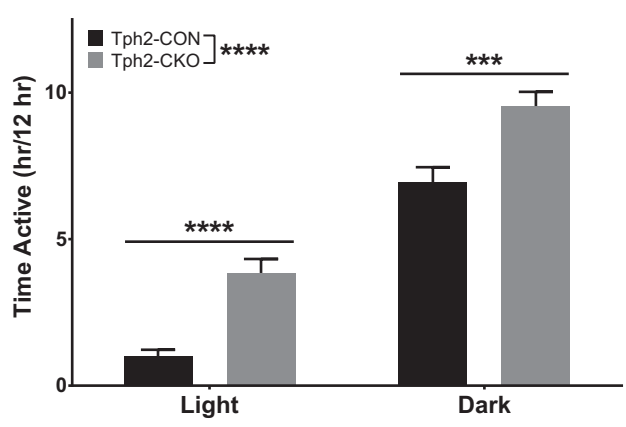

Figure 6. Targeting of adult brain 5 -HT synthesis disrupts daily circadian behavior patterns. $\boldsymbol{A}$, Representative actograms, white bar $=12 \mathrm{~h}$ light period, black bar $=12 \mathrm{~h}$ dark period. $\boldsymbol{B}, 0$ nset (Bi), offset (Bii), and alpha phase length (Biii) $(n=11-12)$. C, Activity counts per hour normalized to total activity $(n=11-12)$. D, Time spent active in light and dark periods ( $n=11-12)$.

These analyses revealed a significant main effect of 5-HT depletion, which resulted in overall increased activity in Tph2-CKO mice compared with Tph2-CON mice (2-way RM-ANOVA; 5 -HT depletion, $F_{(1,21)}=21.749, p=0.0001$; time, $F_{(3.939,82.720)}=$ $75.106, p<0.0001$; 5-HT depletion $\times$ time: $F_{(3.939,82.720)}=4.582$, $p=0.002$, post hoc testing with Sidak's correction, square-roottransformed data). However, there was also a significant interaction between 5-HT depletion and time, meaning that the increased activity in Tph2-CKO mice was only significant at specific time points indicated by post hoc testing, which aligned directly with the changes in circadian behavior patterns (Fig. 7B).

To remove the confounding factor of the differences in duration of activity between Tph2-CON and Tph2-CKO mice, we examined the rates of activity only during bouts of activity, allowing us to determine definitively whether Tph2-CKO mice are hyperactive. Both the peak (2-way RM-ANOVA; 5-HT depletion, $F_{(1,21)}=8.051, p=0.0099$; time, $F_{(1,21)}=63.25, p<0.0001$;
5 -HT depletion $\times$ time, $F_{(1,23)}=0.002652, p=0.9594$; post hoc testing with Sidak's correction, square-root-transformed data; Fig. 7Ci) and average (2-way RM-ANOVA; 5-HT depletion, $F_{(1,21)}=6.691, p=0.0172$; time, $F_{(1,21)}=27.81, p<0.0001$; 5 -HT depletion $\times$ time, $F_{(1,21)}=0.09999, p=0.7550$; post hoc testing with Sidak's correction, log-transformed data; Fig. 7Cii) rates of activity within bouts of activity were significantly increased in Tph2-CKO mice compared with Tph2-CON mice. In addition, even between the offset of one alpha phase and the onset of the next (ZT6-11), activity was increased in Tph2-CKO mice (Tph2-CON $21.40 \pm 12.74$ vs Tph2-CKO $98.08 \pm 67.17$ activity counts, $t$ test, $t_{(21)}=5.555, p<0.0001$, log-transformed data). Together, these data indicate that a deficiency in adult brain 5-HT synthesis results in hyperactivity.

Adult brain 5-HT synthesis is required for the natural siesta Further inspection of the circadian actograms indicated that Tph2-CON mice consistently exhibited a $\sim 2$ h break in activity, 
A

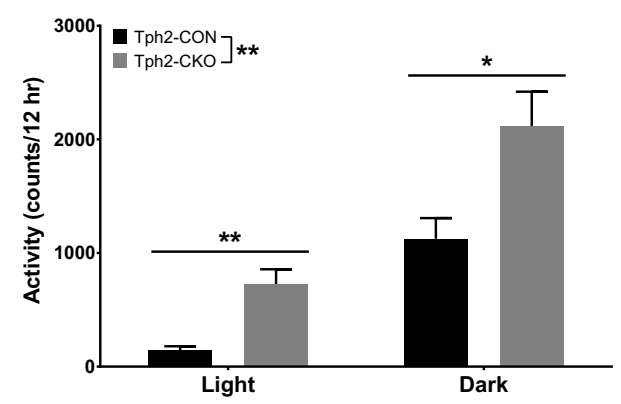

B

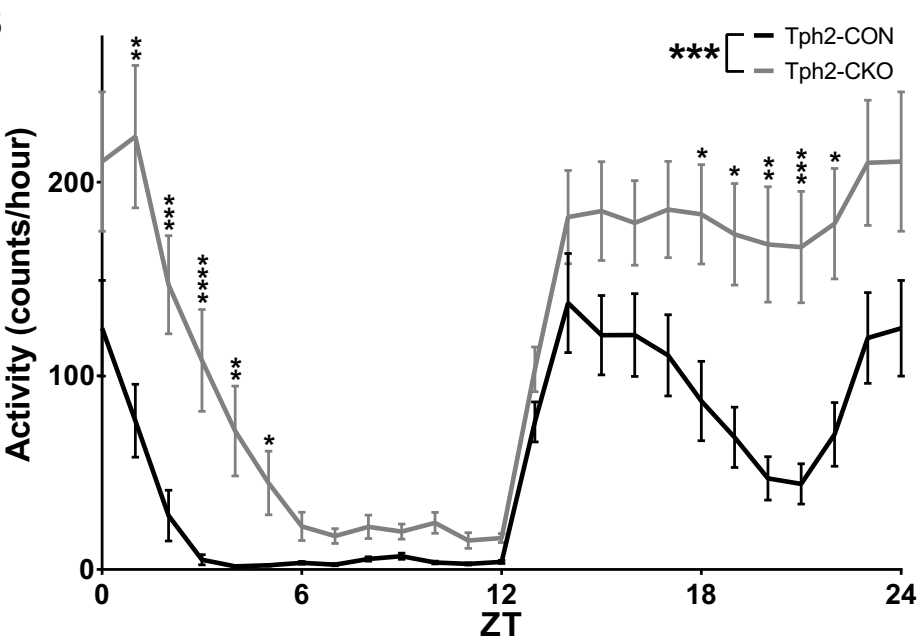

C $\mathrm{i}$

Peak Activity Rate

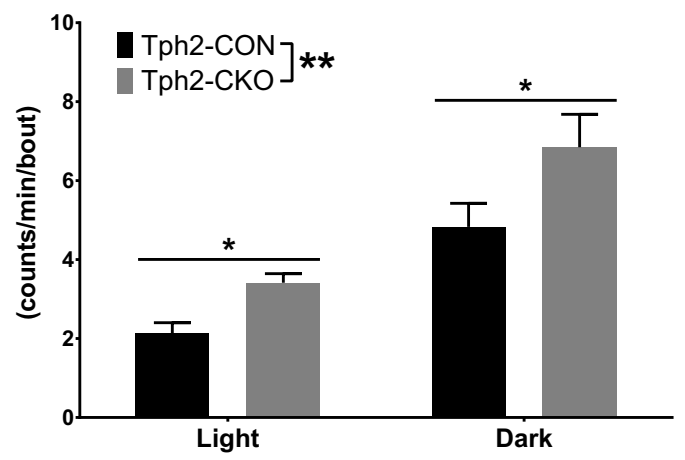

ii

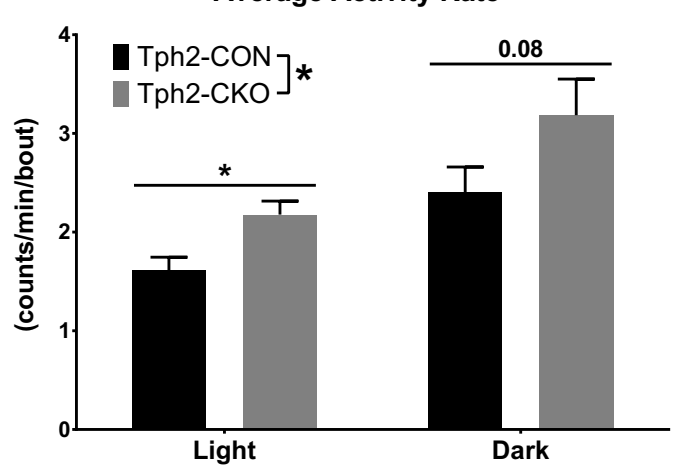

Figure 7. Deficiency of adult brain 5-HT synthesis induces hyperactivity in the home cage environment. $\boldsymbol{A}$, Activity counts in light and dark periods ( $n=11-12$ ). $\boldsymbol{B}$, Activity counts were organized into $1 \mathrm{~h}$ bins, averaged for each mouse, and then averaged across the group for each ZT hour $(n=11-12)$. C, Peak activity rate per bout in light and dark periods (Ci) and average activity rate per bout in light and dark periods (Cii) $(n=11-12)$.

or "siesta," during the second half of the dark phase (Fig. 8Ai). Quantification of time spent active showed that Tph2-CON mice were active for $\sim 2 \mathrm{~h}$ less than Tph2-CKO mice during the dark period, supporting a possible loss of siesta in Tph2-CKO mice (Fig. 6D). To further determine whether the decrease in time spent active was due to a discrete break in activity in Tph2-CON mice, we examined individual activity profile data. Tph2-CON mice consistently exhibited siestas (Fig. 8Aii). The $11 \mathrm{~d}$ average activity profile of mouse \#6068 appears to only show a partial siesta; however, this mouse took full, consistent siestas on days 9-11 (data not shown). Surprisingly, the siesta was absent in every Tph2-CKO mouse with confirmed 5-HT elimination (Fig. 8Aii). Although the $11 \mathrm{~d}$ average activity profile for Tph2-CKO mouse \#5925 showed a dip in dark period ac- tivity, inspection of the actogram for this mouse revealed slight decreases in activity around ZT18-22 over several days, but no siestas (data not shown). In addition, Tph2-CKO mouse \#6070 displayed full, consistent siestas (Fig. 8Aii). However, HPLC analysis of mouse \#6070 revealed 30\% residual 5-HT forebrain levels, so this subject was excluded from all behavior analyses.

To quantify the presence of siestas, we examined normalized activity profile data (Fig. $8 \mathrm{~B}$ ). This revealed a significant decrease in activity in Tph2-CON mice during ZT20-21 compared with the rest of the dark period, whereas Tph2-CKO mice had no significant fluctuations in their dark-phase activity distribution $(t$ tests with Sidak's correction for multiple comparisons, squareroot-transformed data; Fig. $8 B$ ). This is supported by the in- 
A i
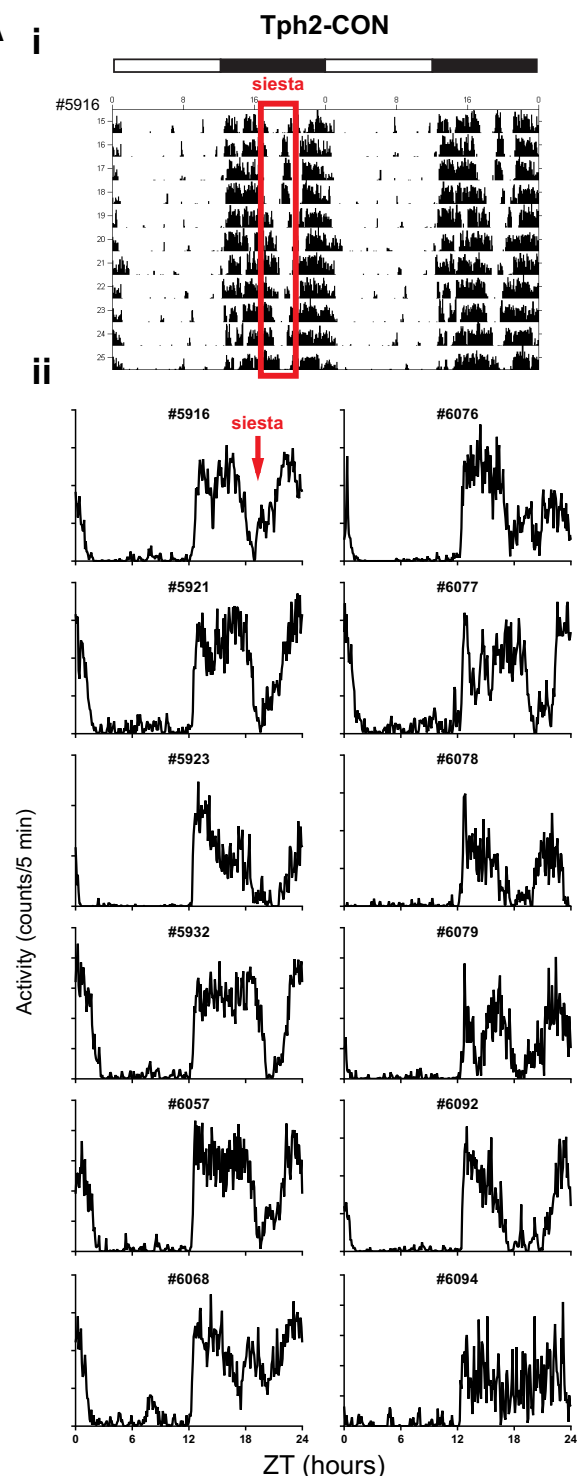

\#6092
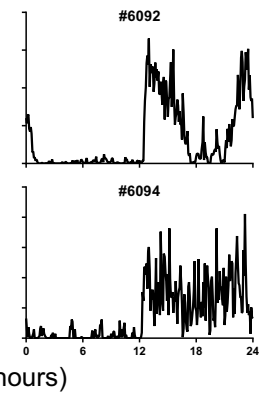

B

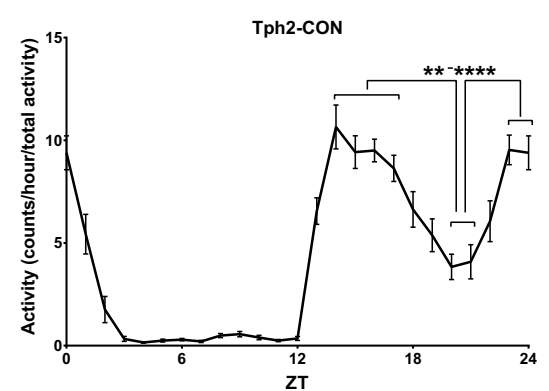

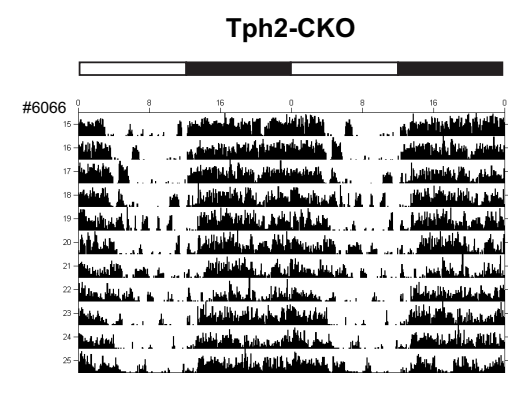
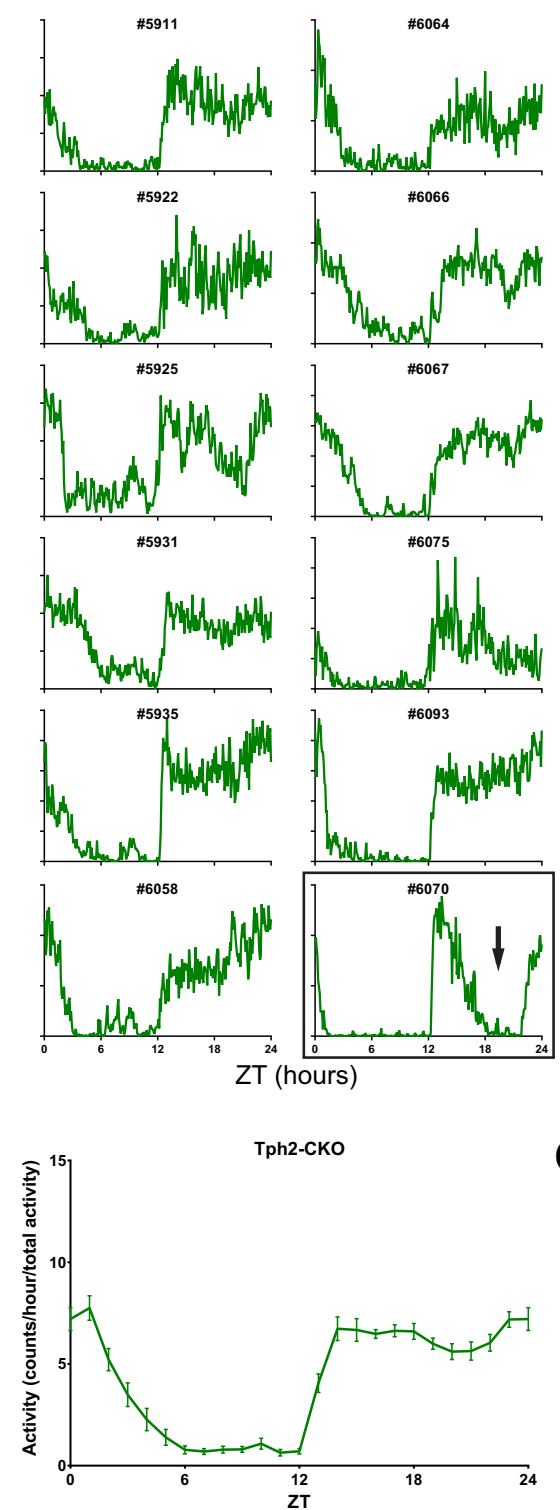

C

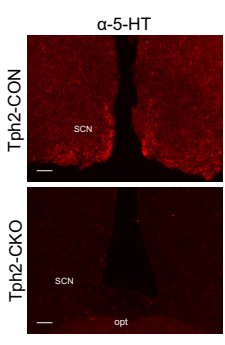

Figure 8. Adult brain 5-HT synthesis is required for the natural siesta. $\boldsymbol{A}$, Representative actograms (Ai) and individual $11 \mathrm{~d}$ average activity profiles (Aii) for all mice included in analysis. Siesta is indicated by the red box on the Tph2-CON actogram and the red arrow on the Tph2-CON activity profile. Tph2-CKO mouse \#6070 had 30\% residual 5-HT by HPLC and exhibited a consistent siesta (black arrow). B, Activity counts were organized into $1 \mathrm{~h}$ bins, averaged for each mouse, averaged across the group for each ZT hour, and normalized to total activity $(n=11-12 ; t$ tests with Sidak's correction for multiple comparisons (Tph2-CON: T20 vs $14^{* * * *}, Z T 20$ vs $15^{* * *} ; Z T 20$ vs $16^{* * * *}, Z T 20$ vs $17^{* * *}, Z T 20$ vs $23^{* * * *}, Z T 20$ vs $24^{* * *}, Z T 21$ vs $14^{* * * *}, Z T 21$ vs $15^{* *}, Z T 21$ vs $16^{* * *}, Z T 21$ vs $17^{* *}$, ZT21 vs $23^{* * *}$, ZT21 vs $24^{* *}$; Tph2-CKO: no significant differences for same comparisons as Tph2-CON, ${ }^{*} p<0.05,{ }^{* *} p<0.01,{ }^{* * *} p<0.001$, and $\left.{ }^{* * * *} p<0.0001\right)$. C, Anti-5-HT immunofluorescence in the SCN of Tph2-CON and Tph2-CKO mice in the optic tract (opt).

creased absolute activity levels of Tph2-CKO mice during ZT18-22 relative to Tph2-CON mice (Fig. $7 B$ ). Importantly, the fact that the loss of siesta in Tph2-CKO mice persisted when the data were normalized for total activity suggests that it is independent of hyperactivity (Fig. 8B). After completion of the study,
5-HT immunoreactivity was shown to be severely depleted in the SCN of Tph2-CKO mice compared with Tph2-CON mice (Fig. 8C). Near-complete eliminations of 5-HT (Tph2-CON $9.744 \pm$ $1.085 \mathrm{vs}$ Tph2-CKO $0.0860 \pm 0.1923 \mathrm{ng} / \mathrm{pg}$ protein, Mann-Whitney $U$ test $=0, p=0.0005, n=5-11)$ and 5-HIAA (Tph2-CON 
$5.524 \pm 0.9925$ vs Tph2-CKO $0.0 \pm 0.0 \mathrm{ng} / \mathrm{pg}$ protein, $t$ test, $\left.t_{(14)}=24.33, p<0.0001, n=5-11\right)$ were confirmed in Tph2CKO mice except for mouse \#6070.

\section{Discussion}

We present a new approach for near-complete elimination of 5-HT synthesis in the ascending 5-HT system of adult mice. Our method targets Tph2 in the anterior raphe nuclei with midbrain/ pontine AAV-Cre injections in adult mice, permitting normal brain maturation and avoiding potential developmental compensatory effects that may arise from fetal targeting of Tph2. Using this technique, we discovered a novel phenotype of hyperactivity with disrupted circadian behavior patterns, including loss of the nocturnal siesta. These findings highlight the importance of our approach in understanding 5-HT's role in the adult brain.

Previous studies using pharmacological and genetic disruptions of the 5-HT system have produced variable results in tests of locomotor activity in novel (open-field) and familiar (home cage) environments. For example, PCPA resulted in normal, decreased, or increased locomotor activity, depending on the study, in novel and familiar environments (Tenen, 1967; Fibiger and Campbell, 1971; Steigrad et al., 1978; Dringenberg et al., 1995). Germline targeting of Tph2 resulted in normal, decreased, or increased locomotor activity, again varying from study to study, in novel and familiar environments (Savelieva et al., 2008; Alenina et al., 2009; Solarewicz et al., 2015; Gutknecht et al., 2015). Importantly, because these studies did not report bout analysis results, there is no indication whether changes in daily, light period, or dark period activity levels were due to alterations in circadian behavior, absolute activity levels, or both.

We examined locomotor activity of Tph2-CON and Tph2CKO mice in a novel open-field environment and familiar home cage environments. In all studies, Tph2-CKO mice exhibited increased total locomotor activity, as well as in the light and dark periods in home cage studies. However, increases in activity might have been caused only by altered circadian behavior patterns, which increased the duration of activity in Tph2-CKO mice, as opposed to absolute hyperactivity. Furthermore, in our circadian study, increased activity in Tph2-CKO mice was only significant during times that aligned with behavior pattern changes: during ZT18-22, when the normal siesta occurs, and during ZT1-5, when the normal active phase tapers off (Fig. 5B). This implied that, even though overall activity was increased, Tph2-CKO mice might have had alterations only in their pattern of activity, not also their absolute activity. However, we determined that adult 5-HT deficiency caused absolute hyperactivity by examining activity within bouts, thus removing the confounding factor of differences in time spent active. This revealed that Tph2-CKO mice had increased average and peak rates of activity during bouts of activity, confirming the presence of hyperactivity. Considering the widely varying previously published results, it is significant that our concordant evidence for hyperactivity was obtained in independent cohorts at three different institutions, during different times of the year, using different experimental setups, and by three different groups of investigators, indicating the robust nature of this phenotype following adult 5 -HT deficiency. Because the forebrain is severely depleted of 5 -HT, it is possible that secondary effects on homeostatic-hypothalamic and other autonomic functions regulated by 5 -HT are affected, which could play a role in the behavioral changes that we observed.
5-HT has long been implicated in the regulation of circadian rhythms and daily activity patterns (Ciarleglio et al., 2011). Release of 5-HT into the SCN has a daily rhythm and 5-HT has been shown to modulate photic and nonphotic input to the SCN (Rea et al., 1994; Dudley et al., 1998; Glass et al., 2003). Our findings revealed that a severe deficiency of adult 5-HT led to altered circadian patterns of daily activity, characterized by an advanced onset of activity, delayed offset of activity, and lengthened alpha phase. Similar changes in the onset and offset of activity have been reported after intraventricular injections of 5,7-DHT and in Pet- $1^{-l-}$ mice (Smale et al., 1990; Paulus and Mintz, 2012; Ciarleglio et al., 2014). Therefore, our results make clear that similar changes consistently observed in other models of 5-HT system hypofunction were in fact due to a specific requirement for 5-HT in adulthood to control normal circadian onset and offset of activity.

Our findings also demonstrated that depletion of adult 5-HT prevented the occurrence of a nocturnal activity break or siesta. Siestas, typically $2 \mathrm{~h}$ long, occur naturally in wild-type mice (Tankersley et al., 2002; Stowie and Glass, 2015), but very little is known about their regulation. In our study, virtually all Tph2CON mice displayed an $\sim 2 \mathrm{~h}$ siesta. In striking contrast, siestas were absent in every Tph2-CKO mouse with confirmed loss of 5-HT. One Tph $2^{f l-}$ mouse injected with AAV-Cre had incomplete 5 -HT depletion (30\% of control by HPLC) and exhibited consistent siestas, further confirming a requirement for 5-HT for siestas. Furthermore, the loss of siestas in Tph2-CKO mice persisted when data were normalized for total activity, suggesting that the failure to take a siesta was independent of the accompanying hyperactivity. Although no previous circadian or sleep studies using a model of 5-HT system hypofunction have reported the presence or lack of a siesta, one study with Pet-1 ${ }^{-/-}$ mice presented findings suggesting siestas occurred in both Pet- $1^{+/+}$and Pet-1 $1^{-1-}$ mice (Wellman et al., 2013), which further supports a specific requirement for adult 5-HT in this behavior.

Two recent studies demonstrated that siestas in wild-type mice are periods of increased rapid eye movement sleep (REMS) and non-REM sleep (NREMS; Dudley et al., 2003; Ehlen et al., 2015). NREM delta power, a measure of the homeostatic drive to sleep, or sleep pressure, also steadily increases during the dark period and peaks at the onset of siesta in wild-type mice. In view of these findings, our data showing that Tph2-CKO mice do not take an extended break in activity during the dark period strongly implicate adult 5-HT in the control of sleep-wake mechanisms and provide evidence that it may largely promote, not suppress, sleep. Subtle decreases in NREMS at lights-on and lights-off have been reported in Tph $2^{-1-}$ mice, but it is unclear whether these changes in NREMS resulted from altered assembly of sleep-wake circuits brought about by developmental deficiency of 5-HT or a specific need for adult 5-HT (Solarewicz et al., 2015). Our results also suggest that adult 5-HT may play a role in the accumulation of sleep pressure and the initiation and maintenance of sleep, as reflected by the loss of siesta and increased activity during the rest phase (ZT6-11). Interestingly, Tph $2^{-1-}$ mice displayed normal levels of NREM delta power over the LD cycle (Solarewicz et al., 2015), raising the possibility that adult 5-HT specifically may be required for sleep pressure accumulation. It will be important in future studies to determine how adult 5-HT deficiency affects REMS/NREMS architecture and sleep pressure accumulation.

Two types of sleep-promoting neurons modulated by 5-HT are located in the ventrolateral preoptic area (VLPO). Type 1 neurons are inhibited by 5-HT, whereas type 2 neurons are activated by 5-HT (Gallopin et al., 2005). 5-HT is suggested to acti- 
vate type 2 neurons during drowsiness to permit the initiation of sleep and type 1 neurons fire to maintain sleep. Retrograde Creexpressing viruses injected into the VLPO of adult Tph $2^{f l}$ mice will help to determine specific forebrain regions through which 5-HT controls siestas and sleep-wake homeostasis (Wu et al., 2012). In summary, our adult Tph2-targeting approach has uncovered the control of siestas in mice as a key function for adult 5-HT and strongly suggests a role for adult 5-HT in sleep-wake homeostasis mechanisms.

In addition to revealing a previously unrecognized role for 5-HT in siestas and clarifying its role in regulating activity and circadian behavior, our results may have important implications for 5-HT in a variety of mental health disorders, including ADHD, seasonal affective disorder, depression, bipolar disorder, and sleep disorders. Although ADHD is thought to be driven by dysregulation of catecholinergic signaling in the brain, some studies have suggested that altered 5-HT signaling may also be involved and selective NE and 5-HT reuptake inhibitors have shown efficacy as a second-line treatment for ADHD (Banerjee and Nandagopal, 2015). Moreover, selective 5-HT reuptake inhibitors reduce hyperactivity in mouse models of ADHD (Hiraide et al., 2013). Our findings support the hypothesis that deficient 5-HT transmission may play a role in the hyperactivity and dysregulated sleep homeostasis associated with ADHD. Psychomotor agitation/retardation and disrupted sleep patterns are core symptoms of and part of the diagnostic criteria for depression, seasonal affective disorder, and bipolar disorder (American Psychiatric Association, 2013). 5-HT has been implicated in these disorders and our results suggest that dysregulated 5-HT signaling could contribute to those specific sequelae (Belmaker and Agam, 2008; Ciarleglio et al., 2011; Mann, 2013). Recent studies have also suggested that disturbances in sleep and circadian rhythms may not be just symptoms of many psychiatric disorders related to 5-HT system dysfunction, but may also be part of their etiology (Jagannath et al., 2013; McClung, 2013). Interestingly, humans naturally take midday naps, which are thought to improve cognition and memory, suggesting that 5-HT's role in siesta may be an important adaptation for life-long maintenance of brain health (Ficca et al., 2010). Finally, it will be important to use our approach to define the potential role of adult 5-HT in many other behaviors, such as stress responses, impulsivity, attention, feeding, novelty-induced hypophagia, and behavioral despair/ anhedonia.

\section{References}

Alenina N, Kikic D, Todiras M, Mosienko V, Qadri F, Plehm R, Boyé P, Vilianovitch L, Sohr R, Tenner K, Hörtnagl H, Bader M (2009) Growth retardation and altered autonomic control in mice lacking brain serotonin. Proc Natl Acad Sci U S A 106:10332-10337. CrossRef Medline

American Psychiatric Association (2013) Diagnostic and statistical manual of mental disorders, Ed 5. Arlington, VA: American Psychiatric Publishing.

Angoa-Pérez M, Kane MJ, Briggs DI, Sykes CE, Shah MM, Francescutti DM, Rosenberg DR, Thomas DM, Kuhn DM (2012) Genetic depletion of brain $5 \mathrm{HT}$ reveals a common molecular pathway mediating compulsivity and impulsivity. J Neurochem 121:974-984. CrossRef Medline

Banerjee E, Nandagopal K (2015) Does serotonin deficit mediate susceptibility to ADHD? Neurochem Int 82:52-68. CrossRef Medline

Baumgarten HG, Björklund A, Lachenmayer L, Nobin A (1973) Evaluation of the effects of 5,7-dihydroxydopamine on serotonin and catecholamine neurons in the rat CNS. Acta Physiol Scand Suppl 391:1-19. Medline

Belmaker RH, Agam G (2008) Major depressive disorder. N Engl J Med 358:55-68. CrossRef Medline

Björklund A, Baumgarten HG, Rensch A (1975) 5,7-Dihydroxytryptamine: improvement of its selectivity for serotonin neurons in the CNS by pretreatment with desipramine. J Neurochem 24:833-835. Medline
Choi S, Jonak E, Fernstrom JD (2004) Serotonin reuptake inhibitors do not prevent 5,7-dihydroxytryptamine-induced depletion of serotonin in rat brain. Brain Res 1007:19-28. CrossRef Medline

Ciarleglio CM, Resuehr HE, McMahon DG (2011) Interactions of the serotonin and circadian systems: nature and nurture in rhythms and blues. Neuroscience 197:8-16. CrossRef Medline

Ciarleglio CM, Resuehr HES, Axley JC, Deneris ES, McMahon DG (2014) Pet-1 deficiency alters the circadian clock and its temporal organization of behavior. PLoS One 9.

Deneris ES (2011) Molecular genetics of mouse serotonin neurons across the lifespan. Neuroscience 197:17-27. CrossRef Medline

Dringenberg HC, Hargreaves EL, Baker GB, Cooley RK, Vanderwolf CH (1995) p-Chlorophenylalanine-induced serotonin depletion: reduction in exploratory locomotion but no obvious sensory-motor deficits. Behav Brain Res 68:229-237. CrossRef Medline

Dudley CA, Erbel-Sieler C, Estill SJ, Reick M, Franken P, Pitts S, McKnight SL (2003) Altered patterns of sleep and behavioral adaptability in NPAS2deficient mice. Science 301:379-383. CrossRef Medline

Dudley TE, DiNardo LA, Glass JD (1998) Endogenous regulation of serotonin release in the hamster suprachiasmatic nucleus. J Neurosci 18: 5045-5052. Medline

Durant C, Christmas D, Nutt D (2010) The pharmacology of anxiety. Curr Top Behav Neurosci 2:303-330. Medline

Ehlen JC, Jones KA, Pinckney L, Gray CL, Burette S, Weinberg RJ, Evans JA, Brager AJ, Zylka MJ, Paul KN, Philpot BD, DeBruyne JP (2015) Maternal Ube3a loss disrupts sleep homeostasis but leaves circadian rhythmicity largely intact. J Neurosci 35:13587-13598. CrossRef Medline

El Mestikawy S, Wallén-Mackenzie A, Fortin GM, Descarries L, Trudeau LE (2011) From glutamate co-release to vesicular synergy: vesicular glutamate transporters. Nat Rev Neurosci 12:204-216. CrossRef Medline

Feil R, Brocard J, Mascrez B, LeMeur M, Metzger D, Chambon P (1996) Ligand-activated site-specific recombination in mice. Proc Natl Acad Sci U S A 93:10887-10890. CrossRef Medline

Fernandez SP, Gaspar P (2012) Investigating anxiety and depressive-like phenotypes in genetic mouse models of serotonin depletion. Neuropharmacology 62:144-154. CrossRef Medline

Fibiger HC, Campbell BA (1971) The effect of para-chlorophenylalanine on spontaneous locomotor activity in the rat. Neuropharmacology 10:25-32. CrossRef Medline

Ficca G, Axelsson J, Mollicone DJ, Muto V, Vitiello MV (2010) Naps, cognition and performance. Sleep Med Rev 14:249-258. CrossRef Medline

Gallopin T, Luppi PH, Cauli B, Urade Y, Rossier J, Hayaishi O, Lambolez B, Fort $P$ (2005) The endogenous somnogen adenosine excites a subset of sleep-promoting neurons via $\mathrm{A} 2 \mathrm{~A}$ receptors in the ventrolateral preoptic nucleus. Neuroscience 134:1377-1390. CrossRef Medline

Gershon MD (2013) 5-Hydroxytryptamine (serotonin) in the gastrointestinal tract. Curr Opin Endocrinol Diabetes Obes 20:14-21. CrossRef Medline

Glass JD, Grossman GH, Farnbauch L, DiNardo L (2003) Midbrain raphe modulation of nonphotic circadian clock resetting and 5-HT release in the mammalian suprachiasmatic nucleus. J Neurosci 23:7451-7460. Medline

Gutknecht L, Waider J, Kraft S, Kriegebaum C, Holtmann B, Reif A, Schmitt A, Lesch KP (2008) Deficiency of brain 5-HT synthesis but serotonergic neuron formation in Tph2 knockout mice. J Neural Transm 115:11271132. CrossRef Medline

Gutknecht L, Popp S, Waider J, Sommerlandt FMJ, Göppner C, Post A, Reif A, Van Den Hove D, Strekalova T, Schmitt A, Colaço MBN, Sommer C, Palme R, Lesch KP (2015) Interaction of brain 5-HT synthesis deficiency, chronic stress and sex differentially impact emotional behavior in Tph2 knockout mice. Psychopharmacology (Berl) 232:2429-2441. CrossRef Medline

Hendricks TJ, Fyodorov DV, Wegman LJ, Lelutiu NB, Pehek EA, Yamamoto B, Silver J, Weeber EJ, Sweatt JD, Deneris ES (2003) Pet-1 ETS gene plays a critical role in 5-HT neuron development and is required for normal anxiety-like and aggressive behavior. Neuron 37:233-247. CrossRef Medline

Hiraide S, Ueno K, Yamaguchi T, Matsumoto M, Yanagawa Y, Yoshioka M, Togashi H (2013) Behavioural effects of monoamine reuptake inhibitors on symptomatic domains in an animal model of attention-deficit/ hyperactivity disorder. Pharmacol Biochem Behav 105:89-97. CrossRef Medline 
Hodges MR, Richerson GB (2010) The role of medullary serotonin (5-HT) neurons in respiratory control: contributions to eupneic ventilation, $\mathrm{CO} 2$ chemoreception, and thermoregulation. J Appl Physiol 108:1425-1432. CrossRef Medline

Jacobs BL, Azmitia EC (1992) Structure and function of the brain serotonin system. Physiol Rev 72:165-229. Medline

Jagannath A, Peirson SN, Foster RG (2013) Sleep and circadian rhythm disruption in neuropsychiatric illness. Curr Opin Neurobiol 23:888-894. CrossRef Medline

Johnson PL, Molosh A, Fitz SD, Arendt D, Deehan GA, Federici LM, Bernabe C, Engleman EA, Rodd ZA, Lowry CA, Shekhar A (2015) Pharmacological depletion of serotonin in the basolateral amygdala complex reduces anxiety and disrupts fear conditioning. Pharmacol Biochem Behav 138: 174-179. CrossRef Medline

Kim JY, Kim A, Zhao ZQ, Liu XY, Chen ZF (2014) Postnatal maintenance of the 5-Htla-Petl autoregulatory loop by serotonin in the raphe nuclei of the brainstem. Mol Brain 7:48. CrossRef Medline

Kim K, Oh CM, Ohara-Imaizumi M, Park S, Namkung J, Yadav VK, Tamarina NA, Roe MW, Philipson LH, Karsenty G, Nagamatsu S, German MS, Kim H (2015) Functional role of serotonin in insulin secretion in a dietinduced insulin-resistant state. Endocrinology 156:444-452. CrossRef Medline

Knuth ED, Etgen AM (2004) Neural and hormonal consequences of neonatal 5,7-dihydroxytryptamine may not be associated with serotonin depletion. Brain Res Dev Brain Res 151:203-208. CrossRef Medline

Koe BK, Weissman A (1966) p-chlorophenylalanine: A specific depletor of brain serotonin. J Pharmacol Exp Ther 154:499-516. Medline

Lerch-Haner JK, Frierson D, Crawford LK, Beck SG, Deneris ES (2008) Serotonergic transcriptional programming determines maternal behavior and offspring survival. Nat Neurosci 11:1001-1003. CrossRef Medline

Lesch K-P, Araragi N, Waider J, van den Hove D, Gutknecht L (2012) Targeting brain serotonin synthesis: insights into neurodevelopmental disorders with long-term outcomes related to negative emotionality, aggression and antisocial behaviour. Philos Trans R Soc B Biol Sci 367: 2426-2443. CrossRef Medline

Liu C, Maejima T, Wyler SC, Casadesus G, Herlitze S, Deneris ES (2010) Pet-1 is required across different stages of life to regulate serotonergic function. Nat Neurosci 13:1190-1198. CrossRef Medline

Mackenzie RG, Hoebel BG, Norelli HC, Trulson ME (1978) Increased tiltcage activity after serotonin depletion by 5,7-dihydroxytryptamine. Neuropharmacology 17:957-963. CrossRef Medline

Mann JJ (2013) The serotonergic system in mood disorders and suicidal behaviour. Philos Trans R Soc Lond B Biol Sci 368:20120537. CrossRef Medline

McClung CA (2013) How might circadian rhythms control mood? Let me count the ways. Biol Psychiatry 74:242-249. CrossRef Medline

Migliarini S, Pacini G, Pelosi B, Lunardi G, Pasqualetti M (2013) Lack of brain serotonin affects postnatal development and serotonergic neuronal circuitry formation. Mol Psychiatry 18:1106-1118. CrossRef Medline

Morin LP (1992) Serotonergic reinnervation of the hamster suprachiasmatic nucleus and intergeniculate leaflet without functional circadian rhythm recovery. Brain Res 599:98-104. CrossRef Medline

Morin LP (1999) Serotonin and the regulation of mammalian circadian rhythmicity. Ann Med 31:12-33. CrossRef Medline

Mosienko V, Bert B, Beis D, Matthes S, Fink H, Bader M, Alenina N (2012) Exaggerated aggression and decreased anxiety in mice deficient in brain serotonin. Transl Psychiatry 2:e122. CrossRef Medline

Mosienko V, Beis D, Pasqualetti M, Waider J, Matthes S, Qadri F, Bader M, Alenina N (2015) Life without brain serotonin: Reevaluation of serotonin function with mice deficient in brain serotonin synthesis. Behav Brain Res 277:78-88. CrossRef Medline

Ohta Y, Kosaka Y, Kishimoto N, Wang J, Smith SB, Honig G, Kim H, Gasa RM, Neubauer N, Liou A, Tecott LH, Deneris ES, German MS (2011) Convergence of the insulin and serotonin programs in the pancreatic $\beta$-cell. Diabetes 60:3208-3216. CrossRef Medline

Paulus EV, Mintz EM (2012) Developmental disruption of the serotonin system alters circadian rhythms. Physiol Behav 105:257-263. CrossRef Medline

Paxinos G, Franklin KBJ (2008) The mouse brain in stereotaxic coordinates, Ed 3. New York: Academic.

Pelosi B, Pratelli M, Migliarini S, Pacini G, Pasqualetti M (2015) Generation of a Tph2 conditional knockout mouse line for time- and tissue-specific depletion of brain serotonin. PLoS One 10:e0136422. CrossRef Medline

Rea MA, Glass JD, Colwell CS (1994) Serotonin modulates photic responses in the hamster suprachiasmatic nuclei. J Neurosci 14:3635-3642. Medline

Reader TA, Gauthier P (1984) Catecholamines and serotonin in the rat central nervous system after 6-OHDA, 5-7-DHT and p-CPA. J Neural Transm 59:207-227. CrossRef Medline

Savelieva KV, Zhao S, Pogorelov VM, Rajan I, Yang Q, Cullinan E, Lanthorn TH (2008) Genetic disruption of both tryptophan hydroxylase genes dramatically reduces serotonin and affects behavior in models sensitive to antidepressants. PLoS One 3:e3301. CrossRef Medline

Schaefer TL, Vorhees CV, Williams MT (2009) Mouse plasmacytomaexpressed transcript 1 knock out induced 5-HT disruption results in a lack of cognitive deficits and an anxiety phenotype complicated by hypoactivity and defensiveness. Neuroscience 164:1431-1443. CrossRef Medline

Smale L, Michels KM, Moore RY, Morin LP (1990) Destruction of the hamster serotonergic system by 5,7-DHT: effects on circadian rhythm phase, entrainment and response to triazolam. Brain Res 515:9-19. CrossRef Medline

Solarewicz JZ, Angoa-Pérez M, Kuhn DM, Mateika JH (2015) The sleepwake cycle and motor activity, but not temperature, are disrupted over the light-dark cycle in mice genetically depleted of serotonin. Am J Physiol Regul Integr Comp Physiol 308:R10-R17. CrossRef Medline

Southwick SM, Paige S, Morgan CA 3rd, Bremner JD, Krystal JH, Charney DS (1999) Neurotransmitter alterations in PTSD: catecholamines and serotonin. Semin Clin Neuropsychiatry 4:242-248. Medline

Steele AD, Jackson WS, King OD, Lindquist S (2007) The power of automated high-resolution behavior analysis revealed by its application to mouse models of Huntington's and prion diseases. Proc Natl Acad Sci U S A 104:1983-1988. CrossRef Medline

Steigrad P, Tobler I, Waser PG, Borbély AA (1978) Effect of p-chlorophenylalanine on cerebral serotonin binding, serotonin concentration and motor activity in the rat. Naunyn Schmiedebergs Arch Pharmacol 305:143-148. CrossRef Medline

Stowie AC, Glass JD (2015) Longitudinal study of changes in daily activity rhythms over the lifespan in individual male and female C57BL/6J mice. J Biol Rhythm 30:563-568. CrossRef Medline

Sziray N, Kuki Z, Nagy KM, Markó B, Kompagne H, Lévay G (2010) Effects of single and simultaneous lesions of serotonergic and noradrenergic pathways on open-space and bright-space anxiety-like behavior in two animal models. Behav Brain Res 209:93-98. CrossRef Medline

Tagliamonte A, Tagliamonte P, Corsini GU, Mereu GP, Gessa GL (1973) Decreased conversion of tyrosine to catecholamines in the brain of rats treated with p-chlorophenylalanine. J Pharm Pharmacol 25:101-103. CrossRef Medline

Tankersley CG, Irizarry R, Flanders S, Rabold R (2002) Circadian rhythm variation in activity, body temperature, and heart rate between $\mathrm{C} 3 \mathrm{H} / \mathrm{HeJ}$ and C57BL/6J inbred strains. J Appl Physiol 92:870-877. Medline

Tenen SS (1967) The effects of p-chlorophenylalanine, a serotonin depletor, on avoidance acquisition, pain sensitivity and related behavior in the rat. Psychopharmacologia 10:204-219. CrossRef Medline

Walther DJ, Bader M (2003) A unique central tryptophan hydroxylase isoform. Biochem Pharmacol 66:1673-1680. CrossRef Medline

Wellman CL, Camp M, Jones VM, MacPherson KP, Ihne J, Fitzgerald P, Maroun M, Drabant E, Bogdan R, Hariri AR, Holmes A (2013) Convergent effects of mouse Pet-1 deletion and human PET-1 variation on amygdala fear and threat processing. Exp Neurol 250:260-269. CrossRef Medline

Wu Q, Clark MS, Palmiter RD (2012) Deciphering a neuronal circuit that mediates appetite. Nature 483:594-597. CrossRef Medline

Wuttke W, Björklund A, Baumgarten HG, Lachenmayer L, Fenske M, Klemm HP (1977) De- and regeneration of brain serotonin neurons following 5,7-dihydroxytryptamine treatment: effects on serum LH, FSH and prolactin levels in male rats. Brain Res 134:317-331. CrossRef Medline

Wyler SC, Spencer WC, Green NH, Rood BD, Crawford L, Craige C, Gresch P, McMahon DG, Beck SG, Deneris E (2016) Pet-1 switches transcriptional targets postnatally to regulate maturation of serotonin neuron excitability. J Neurosci 36:1758-1774. CrossRef Medline

Zhao ZQ, Scott M, Chiechio S, Wang JS, Renner KJ, Gereau RW 4th, Johnson RL, Deneris ES, Chen ZF (2006) Lmxlb is required for maintenance of central serotonergic neurons and mice lacking central serotonergic system exhibit normal locomotor activity. J Neurosci 26:12781-12788. CrossRef Medline 